\author{
Florens Felten \\ Claus Reinholdt \\ Eduard Pollhammer \\ Walter Gauss \\ Rudolfine Smetana
}

\title{
Ägina-Kolonna 2005 \\ Vorbericht über die Grabungen des Fachbereichs Altertumswissenschaften/Klassische und
Frühägäische Archäologie der Universität Salzburg
}

Einleitung

Die Arbeiten der Kampagne des Jahres $2005^{1}$ betrafen den Westkomplex (Südbau: Ostraum, Hof; Ostterrasse: Oststraße, Ostbau I) und seine südliche Anschlusszone, die Fortführung der stratigraphischen Untersuchungen im Bereich 'Südhügel', Restaurierungsarbeiten an der prähistorischen und historischen Bausubstanz sowie die graphisch-didaktische Komplettierung der Exponatpräsentation in den Ausstellungsflächen des Museums von Kolonna.

\section{Westkomplex}

a. Südbau

Im Südbau, der während der vorangegangenen zwei Kampagnen auf seiner Gesamtlänge von $14 \mathrm{~m}$ aufgedeckt worden war (Abb. 1. 2), erfolgten Untersuchungen auf einer Restfläche, die durch spätere Überbauung bislang verschlossen war. Hierdurch ließen sich zusätzliche Aufschlüsse für die bauliche Gestaltung, die Errichtungszeit sowie die Spätzeit des Gebäudekomplexes gewinnen. Darüber hinaus erbrachten Arbeiten in den tieferen Straten überraschende Ergebnisse zur vorerrichtungszeitlichen Nutzung des Geländes.

\section{Ostraum/Hof}

In und über dem Ostraum sowie über einem Teil des südlich anschließenden Hofareals standen noch die ca. $90 \mathrm{~cm}$ dicke Verfüllung aus dem ursprünglichen Lehmziegel-Wandaufbau sowie die darüber verlegte hellenistische Pflasterung aus Architekturspolien an². Eine Abnahme des zu großen Teilen bereits durch die Altgrabung A. Furtwänglers und G. Welters zerstörten Plattenbelags wurde aufgrund des zunehmend schlechten Erhaltungszustands notwendig. Die Pflasterung enthielt mehrere Geisonblöcke ionischer Form mit ein-

\footnotetext{
${ }^{1}$ Gesamtleitung der Arbeiten: F. Felten; Grabungsleitung Westkomplex: C. Reinholdt; Grabungsleitung Südhügel: R. Smetana, W. Gauß; Photographie und Layout: M. Del-Negro, C. Reinholdt, W. Gauß, R. Smetana; Fundverwaltung, Koordination und Museumsarbeiten: V. Felten; Fundbearbeitung Westkomplex: G. Klebinder-Gauß, V. Jarosch-Reinholdt; Mitarbeiter/innen: V. Dimitriou, M. Hinterhöller, D. Knauseder, D. Leiner, A. Paule, G. Schmidhuber, R. Steinhübl, S. Tischler, M. Wiesmüller, B. Wille; Architekturaufnahme: E. Pollhammer, V. Leitner; Fundrestaurierung: T. Tzekou, B. Schneider; Finanzierung: Paris-Lodron-Universität Salzburg, Fonds zur Förderung der wissenschaftlichen Forschung (Wien), Institute of Aegean Prehistory (Philadelphia), Dr. G. Schuhfried (Mödling), Dr. H. Wiesmüller (Salzburg), KR A. Feistl (Wien). Die Unterzeichneten danken E. Konsolaki-Iannopoulou und E. Papastavrou, 16. Ephorie für Prähistorische und Klassische Altertümer (Piräus), für freundliche Unterstützung; zu den früheren Kampagnen vgl. F. Felten u. a., Ägina-Kolonna 2002, ÖJh 72, 2003, 41 ff.; dies., Ägina-Kolonna 2003, ÖJh 73, 2004, 97 ff.; dies., Ägina-Kolonna 2004, ÖJh 74, 2005, 8 ff.

2 s. Felten u. a. (Anm. 1:2003) 43 f. Abb. 3-4.
} 


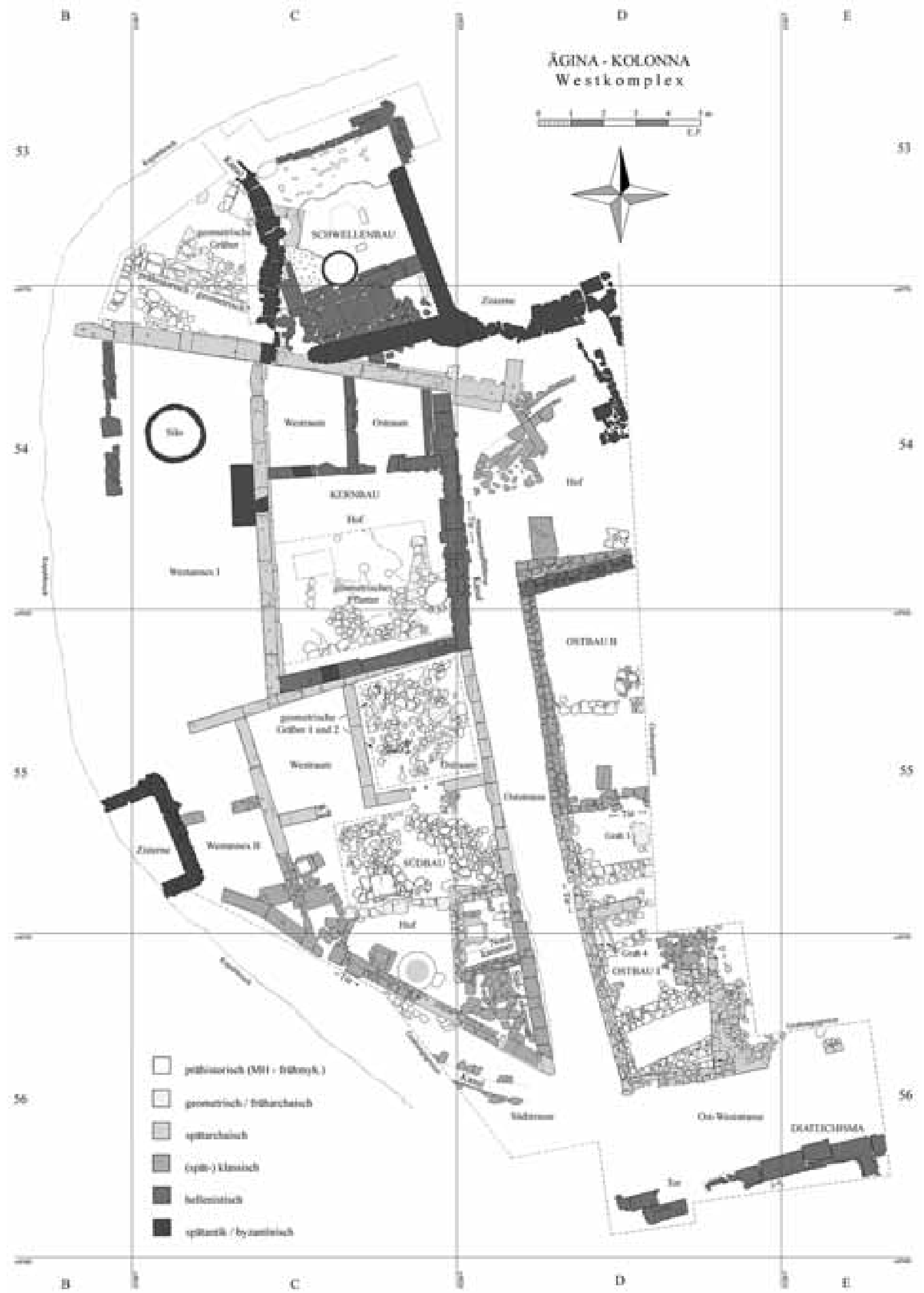

1 Westkomplex. Gesamtplan der Grabungsfläche B-E/53-56 mit Phasenkennzeichnung 


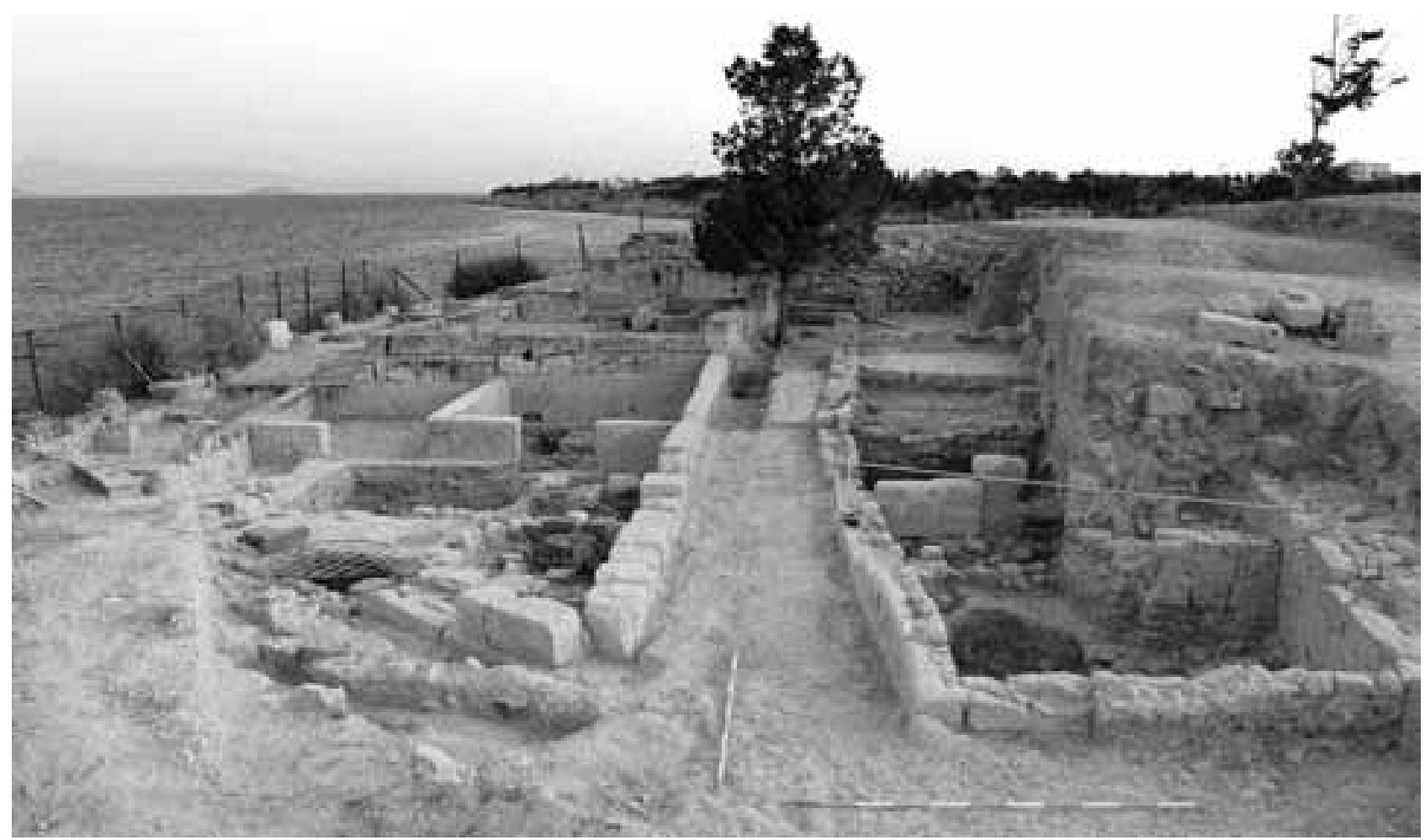

2 Ägina-Kolonna. Westkomplex. Gesamtansicht von Süden

und beidseitiger Hängeplatte (Abb. 3) ${ }^{3}$. Mit einem größeren Altbestand aus dem Bereich des Westkomplexes und in der byzantinischen Verbauung an anderen Stellen der Akropolis lassen sich die Geisa zu einem Dutzend seriengleicher Exemplare zusammenschließen. Typologisch sind sie mit Horizontal- und Traufgeisa des späten 6. und frühen 5. Jahrhunderts v. Chr. auf den Kykladen zu verbinden ${ }^{4}$ und belegen einmal mehr den bereits früher festgestellten deutlichen Einfluss kykladischer Architekturströmungen auf Ägina ${ }^{5}$. Die originale Position der Geisa kann bislang nicht bestimmt werden, möglicherweise haben die Stücke mit duplexer Traufnase ${ }^{6}$ ursprünglich als oberer Wandabschluss der massiven Hofwände des Westkomplexes gedient. Darüber hinaus wurde aus dem Spolienbelag das Fragment einer beschrifteten Statuenbasis geborgen (Abb. 4).

Die folgenden Untersuchungen unter der Pflasterung erbrachten eine dichte Abfolge unterschiedlicher Nutzungsstraten (Abb. 11): Die Pflasterunterfüllung enthielt Fragmente hellenistischer Reliefkeramik sowie

${ }^{3}$ Die Eingriffe der Altgrabung sind auch durch die Anpassung des verworfenen, im alten Grabungsschutt geborgenen Geisonfragmentes Inv. AR 23 an das noch in der Pflasterung befindliche Stück Inv. AF 242 ersichtlich.

${ }^{4}$ Bauglieder und Dächer werden im Rahmen des vom FWF finanzierten und vom Zweitunterzeichneten geleiteten Forschungsprojekts »ALT-ÄGINA. Studien zu Sakral- und Profanarchitektur, Bauornamentik und Wasserversorgung in Heiligtum und Festung « von E. Pollhammer untersucht; zu ähnlichen Geisa vgl. A. Plassart, Les Sanctuaires et les Cultes du Monte Cythe, Délos XI (1928) 198 Abb. 164; R. Vallois, L’architecture hellénique et hellénistique à Délos II 2 (1978) 312; Ph. Fraisse - Ch. Llinas, Documents d’Architecture Hellénique et Hellénistique, Délos XXXVI (1995) 150 f. Abb. 558-564.

${ }^{5}$ Zu den kykladischen Tendenzen in der Architektur Äginas bereits A. Ohnesorg in: M. Schuller, Der Artemistempel im Delion auf Paros (1991) 120 ff.; H. Bankel, Der spätarchaische Tempel der Aphaia auf Aegina (1993) 170 ff.; G. Gruben, Griechische UnOrdnungen, DiskAB 6 (1996) 74 mit Anm. 43; K. Hoffelner - M. Kerschner, Die Sphinxsäule. Votivträger, Altäre, Steingeräte. Perirrhanterien und Becken, Alt-Ägina II 4 (1996) 19 ff. 30 ff. 37 ff.

${ }^{6}$ Doppelseitige Geisa späterer Zeitstellung: J. T. Clarke - H. Bacon - R. Koldewey, Investigations at Assos (1902) 176. 179 Nr. 4; T. Wiegand - H. Schrader, Priene (1904) 260 f. Abb. 263; P. Wolters - G. Bruns, Das Kabirenheiligtum bei Theben I (1940) 19 Taf. 4, 2; E. Dyggve - V. Poulsen, Le Sanctuaire d'Athena Lindia et l'Architecture Lindienne. Lindos. Fouilles de l'acropole 1902-1914 et 1953, Lindos III 1 (1960) 232 Taf. 6 G, II; A. v. Gerkan - W. Müller-Wiener, Das Theater von Epidauros (1961) 66 Taf. 25; D. Pinkwart - W. Stammnitz, Peristylhäuser westlich der unteren Agora, AvP XIV (1984) 29 Abb. 10; Vallois (Anm. 4) 320 f.; Fraisse - Llinas (Anm. 4) 157 Abb. 591-593; 161 Abb. 602. 603; I. C. Love, AJA 77, 1973, 421 ff. Taf. 78 Abb. 23-25; H. Bankel, Knidos. Das Triopion, in: Macht der Architektur. Architektur der Macht, DiskAB 8 (2004) 104 f. Abb. 10. 

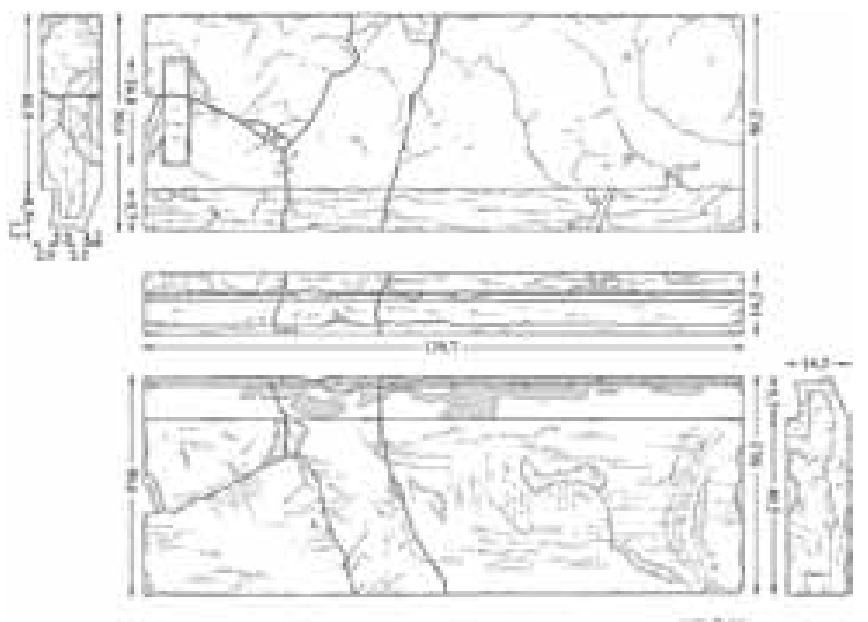

A 241
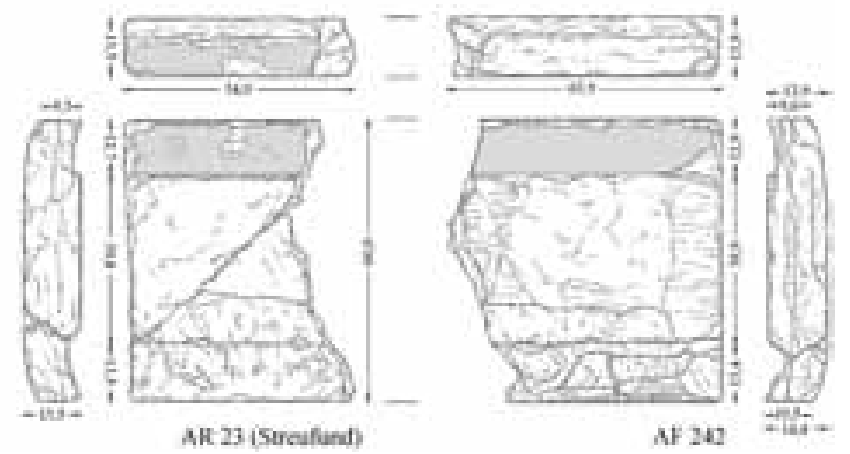

3 Geisonblöcke aus der hellenistischen Spolienpflasterung über dem Südbau

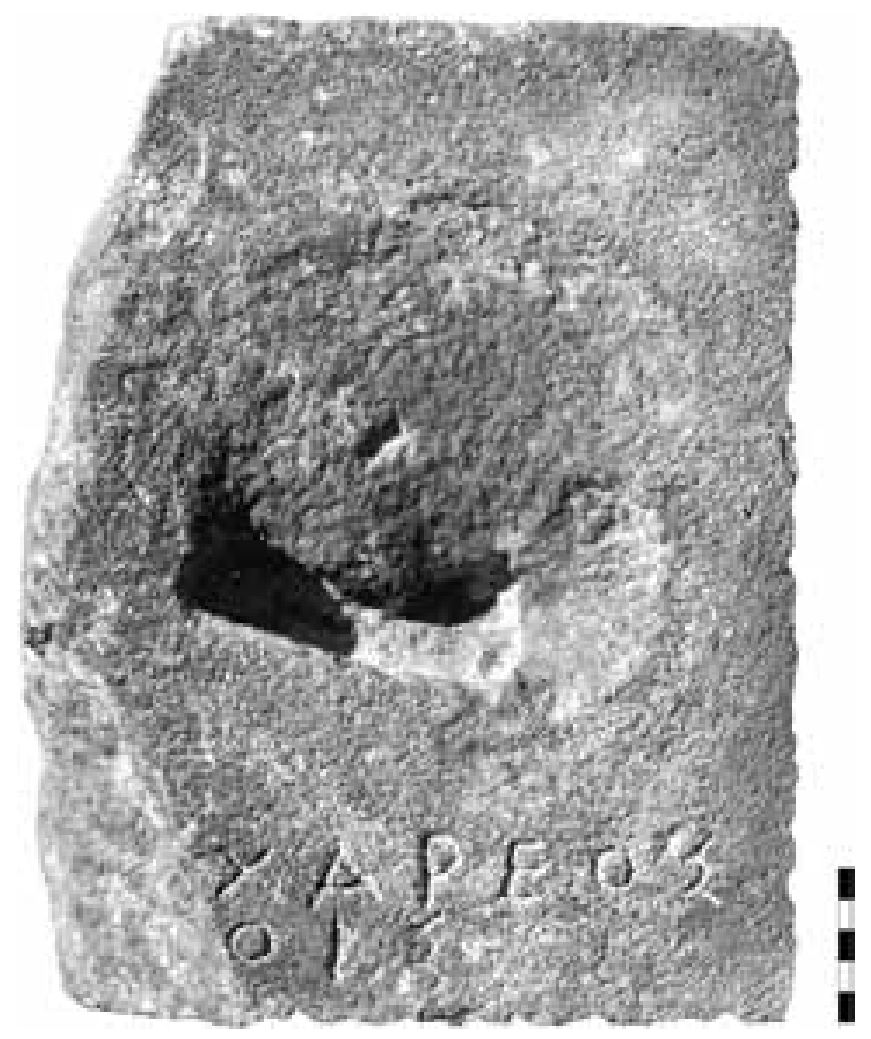

4 Inschriftenbasis aus der Spolienpflasterung
Westabhang-Ware und reicht bis auf einen zementharten, rötlichen Boden, der an seinem östlichen Ende niveaugleich mit den abgetretenen und von Spurrillen durchzogenen Quadern der Ostwand des Südbaus ${ }^{7}$ abbindet (+9.05 m). Dieser hartgetretene Laufhorizont, auf dem sich die Wagenspuren der Quaderoberseiten partiell fortsetzen, ist zugleich die Oberfläche der in Ost- und Westraum sowie in den Hof eingefüllten Lehmziegelmasse der ursprünglichen Wandaufbauten. Der betreffende Bereich des Südbaus hat nach der Verfüllung seiner Kammern und eines Hofteils als offene, auch von Wagenverkehr frequentierte Nutzfläche gedient. In den unteren Straten der Verfüllung traten verstärkt Dachziegelbruch und Keramikschutt auf, die sich mit weiterem Material auf einem grauen Lehmestrich verbinden lassen. Dieser Fußboden (Boden 1; +8.18 m) repräsentiert die letzte Nutzungsphase des Gebäudes.

Mit der Abnahme der Lehmziegelverfüllung wurde die $1.08 \mathrm{~m}$ breite Türöffnung des Ostraumes freigelegt (Abb. 5, 1-2). Von der Türkonstruktion haben sich zwei rechteckige, an das Gewände anschließende Angellöcher, ein ausmittig positioniertes Riegelloch sowie das $20 \mathrm{~cm}$ breite Auflager für den vermutlich in Gestalt einer hölzernen Schwelle verlegten Anschlag erhalten. Vertikale Ausfalzungen an den Stirnseiten des Gewändes belegen eine Verkleidung der Laibungen mit einer hölzernen Schalung.

Die Keramik auf Boden 1, darunter Fragmente von Trink- und Mischgefäßen, Vorrats- und Kochware sowie eine gut erhaltene Amphora ostionischer Produktion (Abb. 6) ${ }^{8}$, erlaubt es, die letzte Nutzung des Südbaus sowie dessen abschließende Verfüllung dem späteren 5. Jahrhundert v. Chr. zuzuweisen. In der Füllung von Boden 1 im Ostraum (+8.18-8.10 m) fand sich grob- und dünnwandige Gebrauchskeramik frühklassischer Zeitstellung. Der letzte feste Boden im Ostraum dürfte in der ersten Hälfte des 5. Jahrhunderts v. Chr. verlegt worden sein.

Unter Boden $1 \mathrm{im}$ Ostraum sowie der aschigen Lage im nördlichen Hofanschluss verläuft ein tieferer Boden aus grauem und hartem Lehmestrich (Boden 2; +8.10 m). Dieser Fußboden wurde im Ostraum auf gesamter Fläche sowie im Hof ange-

\footnotetext{
s. Felten u. a. (Anm. 1:2003) 44 Abb. 3; 47.

${ }^{8}$ Die Transport- und Küchenware sowie die Schwarzfirniskeramik werden von G. Klebinder-Gauß im Rahmen eines vom FWF finanzierten Projekts bearbeitet und vorgelegt.
} 

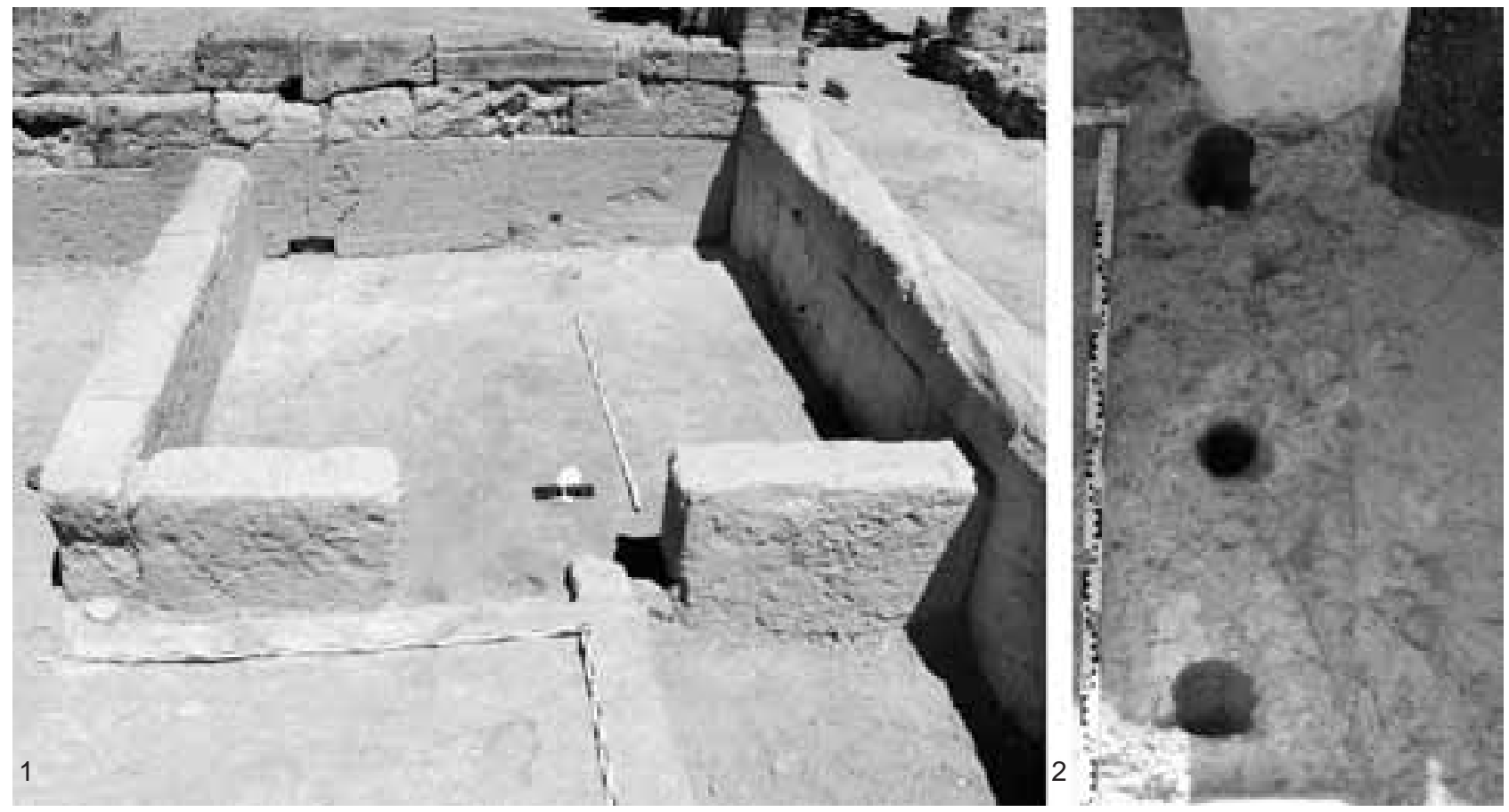

5 Südbau, Ostraum mit errichtungszeitlichem Boden 2 von Süden (1) und Reste der Türkonstruktion (2)

troffen. Die Lauffläche gehört in die Errichtungszeit der gesamten Anlage ${ }^{9}$. Im Hofbereich, unmittelbar vor den Kammern, ruhte die Bodenunterfüllung auf einer dichten Bettung aus Porosabschlag, der bei der Herrichtung der Werkstücke angefallen war. Die in der Füllung befindliche archaische Keramik (Abb. 7, 1) bestätigt das bereits früher angenommene Datum für die Errichtung des Südbaus im ausgehenden 6. bzw. beginnenden 5. Jahrhundert v. Chr.

Der errichtungszeitliche Fußboden 2 liegt über einer im gesamten Südbau und seinen Annexen festgestellten Lauffläche (Boden 3; +7.92 m), deren bauliches Verhältnis zu den gebauten Orthostatenstrukturen ${ }^{10}$ bereits durch die Untersuchungen des Jahres 2004 geklärt werden konnte ${ }^{11}$. Auch im Ostraum sowie im angrenzenden Hofbereich war Boden 3 auf gesamter Fläche vorhanden. Der Laufhorizont zieht unter den Orthostaten des Ostraumes sowie der Ostwand des Südbaus knapp hindurch, sodass die großformatigen Blöcke z. T. direkt auf ihm ruhen. Dieser Fußboden geht dem Quaderund Orthostatenverband des Südbaus voraus und repräsentiert eine großflächige Nutzung des Areals vor den baulichen Maßnahmen in spätarchaischer Zeit. Nach einer ersten Durchsicht zu schließen, reicht das keramische Material in seiner Füllung kaum über die Mitte des 6. Jahrhunderts v. Chr. hinunter (Abb. 7, 2). Boden 3 lässt sich mit einer $4 \mathrm{~m}$

\footnotetext{
${ }^{9}$ s. Felten u. a. (Anm. 1:2003) 48 f.; Felten u. a. (Anm. 1:2004) 113; hier als Boden 3 bezeichnet.

${ }^{10}$ s. Felten u. a. (Anm. 1:2003) 48.

11 s. Felten u. a. (Anm. 1:2005) 10.
}

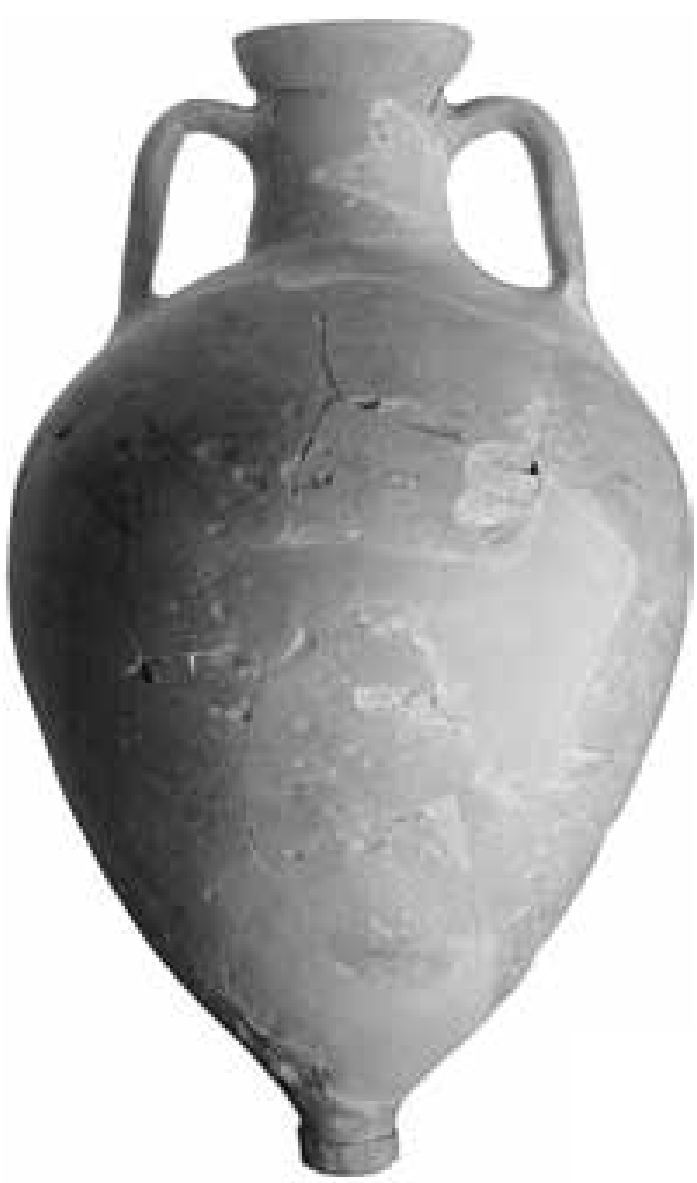

6 Ostraum/Hof. Transportamphora aus dem Stratum der letzten Nutzungsphase 

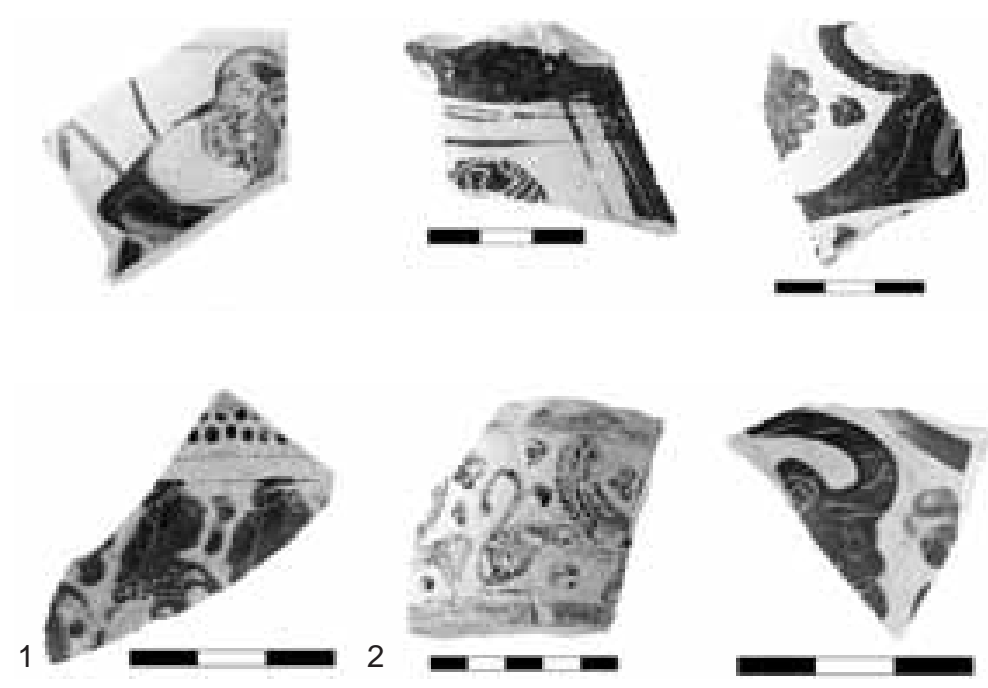

7 Ostraum. Keramik aus den Böden 2 (1) und 3 (2). Auswahl

langen, durch drei Stützenpostamente gegliederten Struktur verbinden, die bei der Anlage von Südbau und Hof noch partiell in Benutzung gewesen ist ${ }^{12}$ und vielleicht als kleine Eingangsloggia für die neuen Raumkammern gedient hat.

Eine weitere bauliche Besonderheit, die im Zusammenhang mit den auf tieferem Niveau im Ostraum festgestellten Befunden an Bedeutung gewinnt, ergab sich im Bereich der Nordostecke. Hier wurde ein $50 \mathrm{~cm}$ langer, grober Stein in Hochkantstellung in einer seichten, grubenförmigen Eintiefung freigelegt (Abb. 8, 1). Die Spitze des stelenförmig aufragenden Steins $(+8.07 \mathrm{~m})$ war von der Lauffläche des Bodens 2 knapp überzogen, ragte aber $15 \mathrm{~cm}$ über die Oberfläche von Boden 3 frei heraus.

Mit den folgenden Abhüben im Ostraum und Hof ergab sich für beide Zonen ein im Wesentlichen übereinstimmendes Bild. Es traten vermehrt Ansammlungen von mittelgroßen und großen Rollsteinen auf. Im Ostraum erschienen sie zu beiden Seiten des 'Steinmales' $10 \mathrm{~cm}$ unter der Lauffläche von Boden 3 (bei $+7.81 \mathrm{~m}$ ) bei nordseitig leicht ansteigendem Oberkantenniveau. Diese Konzentration an Steinmasse erscheint z. T. planlos und willkürlich verworfen, erweckt aber auch den Eindruck gebauter mauerförmiger Strukturen, in deren Verband für eine offensichtlich großflächige Planierung eingegriffen worden ist. Hierbei ließen sich zwei dunkle, erdige Laufhorizonte identifizieren (Boden 4, +7.74 m; Boden 5, +7.60/+7.51 m), die an die Steinsetzungen heranführten (Abb. 11). Die in Boden 3 und den darunter befindlichen Nutzungshorizonten enthaltene, stark zerscherbte Keramik bestand zu geringerem Anteil aus attischer Schwarzfirnisware, vorwiegend aber aus korinthischer Keramik des früheren 6. Jahrhunderts v. Chr. (Abb. 9, 1). Die unteren Lagen enthielten vermehrt Keramik der Mittelbronzezeit und frühmykenischen Epoche (Abb. 9, 2).

Mit der tiefsten Lauffläche wurden in der Nordwestecke sowie im Bereich der Südwestecke die Oberkanten zweier Hockerbestattungen festgestellt (Abb. 10) ${ }^{13}$. Das Grab in der Nordwestecke (Grab 2) war in seiner
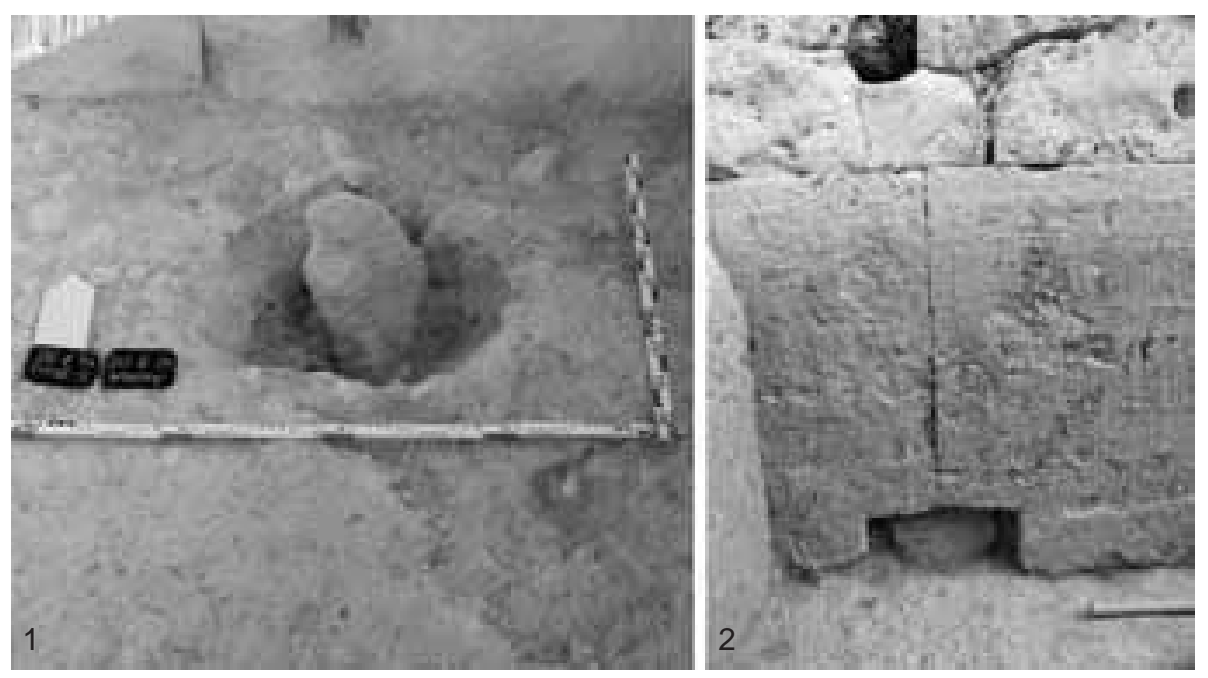

8 Ostraum. Stelenmarkierungen in der Nordostecke (1) und unter der Nordwand (2)

\footnotetext{
12 s. Felten u. a. (Anm. 1:2005) $10 \mathrm{f}$.

${ }^{13}$ Hockerstellung bei protogeometrischen Inhumationen wurden in der früheren Forschung nicht als Regelfall angesehen, vgl. D. C. Kurtz - J. Boardman, Greek burial customs (1971) 54 f.
} 
südlichen Hälfte mit zwei Steinplatten bedeckt, während am nördlichen Ende die Abdeckung fehlte. Das Grab war ohne keramische Beigaben, jedoch erlaubt der vorhandene Bronze- und Eisenschmuck (Abb. 12) aufgrund von Parallelen in Athen und der Argolis eine Datierung der Bestattung in die protogeometrische Zeit. An den Händen, jeweils am Zeigefinger aufgeschoben, befanden sich bronzene Fingerringe (Abb. 12, 2-3), einer aus aufgewickeltem Blech ${ }^{14}$, der andere massiv mit verbreiterter Ringplatte ${ }^{15}$. Der übrige Schmuck erwies sich wie auch der Großteil des Skelettverbandes als sekundär gestört. Dies gilt für einen kleinen Ohrring aus dünnem Bronzeblech (Abb. 12, $4)^{16}$, eine gut erhaltene Eisennadel mit Kugelkopf und Endscheibe aus Elfenbein
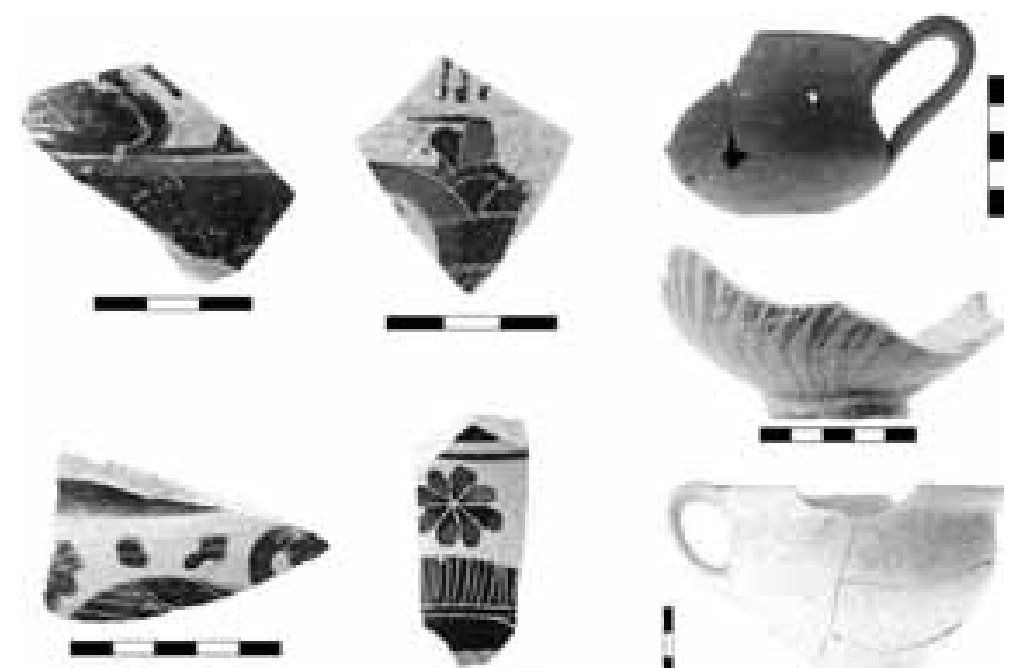

1

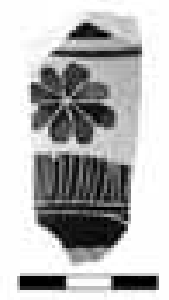

9 Ostraum. Archaische (1) und prähistorische (2) Keramik aus den Planierungsstraten. Auswahl (Abb. 12, 1) 17 $^{17}$ die in mehreren Fragmenten im gesamten Grabschacht verteilt war, sowie für das Fragment eines eng eingerollten Eisenstiftes (Abb. 12, 5), bei dem es sich um den Rest der Nadelrolle einer Eisenfibel handelt ${ }^{18}$. Bügel, Nadel und Nadelhalter wurden nicht angetroffen. Die zweite Bestattung war mit zwei bronzenen Lockenringen aus Wickeldraht ausgestattet (Grab 1). Einer der Ringe besaß Schlaufenenden, der andere einen aufgebogenen Abschluss (Abb. 12, 6-7) ${ }^{19}$. Die obere Grabschachtmauerung und die Schädelkalotte des Skeletts erwiesen sich als sekundär gekappt. In beiden Gräbern ruhten die Skelette auf einer dichten Bettung aus kleinen Flusskieseln, Schnecken und Muscheln (+7.35 m; +7.22 m). Andere länglich-ovale Setzungen kleiner bis mittelgroßer Rollsteine inmitten der Steinansammlung des Ostraumes erweckten den Eindruck weiterer Bestattungen, waren jedoch fundleer.

Die Gräber unter dem Ostraum erhalten im Zusammenhang mit den während früherer Kampagnen im Westraum, in den tieferen Schichten des Kernbaus sowie der Norderweiterung gemachten Befunden besondere Bedeutung. Unter dem Kernbau wurden 2003 auf geringfügig höherem Niveau Nutzungshorizonte mit proto- und frühgeometrischer Keramik sowie zwei runde Pflasterungen freigelegt, die aufgrund von Parallelen in Asine, Naxos, Eleutherna, Milet und Troia mit Praktiken des früheisenzeitlichen Grabkultes in Verbindung zu bringen sind ${ }^{20}$. Möglicherweise gehören auch zwei weiter nördlich freigelegte Kinderbestattungen dazu $^{21}$. Ferner wurde 2002 im Westraum des Südbaus das Segment einer Aschengrube aufgedeckt, die neben wenigen prähistorischen Scherben vorwiegend protogeometrische Keramik und Knochen enthielt ${ }^{22}$. In diese

\footnotetext{
${ }^{14}$ H. Müller-Karpe, Die Metallbeigaben der früheisenzeitlichen Kerameikos-Gräber, JdI 62, 1977, 62 ff. Abb. 12, 4; 26, 4; K. Kokkou-Buride, AEphem 1977, 177 Abb. 4; Taf. 55 $-\theta$ (Argos); I. Kilian-Dirlmeier, Kleinfunde aus dem Athena Itonia-Heiligtum bei Philia/Thessalien (2002) Taf. 10.

${ }_{15}$ Müller-Karpe (Anm. 14) 84 Abb. 2, 10; 87 Abb. 5, 3 (noch submykenisch); Kilian-Dirlmeier (Anm. 14) Taf. 8. 9.

${ }^{16}$ Müller-Karpe (Anm. 14) 84 Abb. 2, 13 (noch submykenisch); Kilian-Dirlmeier (Anm. 14) Taf. 8; M. R. Popham - L. H. Sackett - P. Themelis (Hrsg.), Lefkandi I (1979) Taf. 99, 22.

17 B. Schlörb-Vierneisel, Eridanos-Nekropole, AM 81, 1966, 7 Taf. 11, 1; Müller-Karpe (Anm. 14) 95 Abb. 13, 3. 4; 99 Abb. 17 , 1. 2 mit Bronzeköpfen; I. Kilian-Dirlmeier, Nadeln der frühhelladischen bis archaischen Zeit von der Peloponnes, PBF XIII 8 (1984) Taf. 11.

${ }^{18}$ E. L. Smithson, The Protogeometric Cemetery at Nea Ionia, 1949, Hesperia 30, 1961, 147 ff. Taf. 27, 58. 59; Müller-Karpe (Anm. 14) Abb. 12, 5; 15, 1; 16, 10; 26, 16. 17; 27, 2. 3; Popham - Sackett - Themelis (Anm. 16) Taf. 101, 32; 203.208.

${ }_{19}$ Müller-Karpe (Anm. 14) 84 Abb. 2, 8 (noch submykenisch); Kilian-Dirlmeier (Anm. 14) Taf. 10.

20 s. Felten u. a. (Anm. 1:2004) 107 f. mit Anm. 21 Abb. 10-11.

${ }^{21}$ Felten u. a. (Anm. 1:2004) 104 f. Abb. 6. 7.

22 s. Felten u. a. (Anm. 1:2003) 48 Abb. 9; 49.
} 


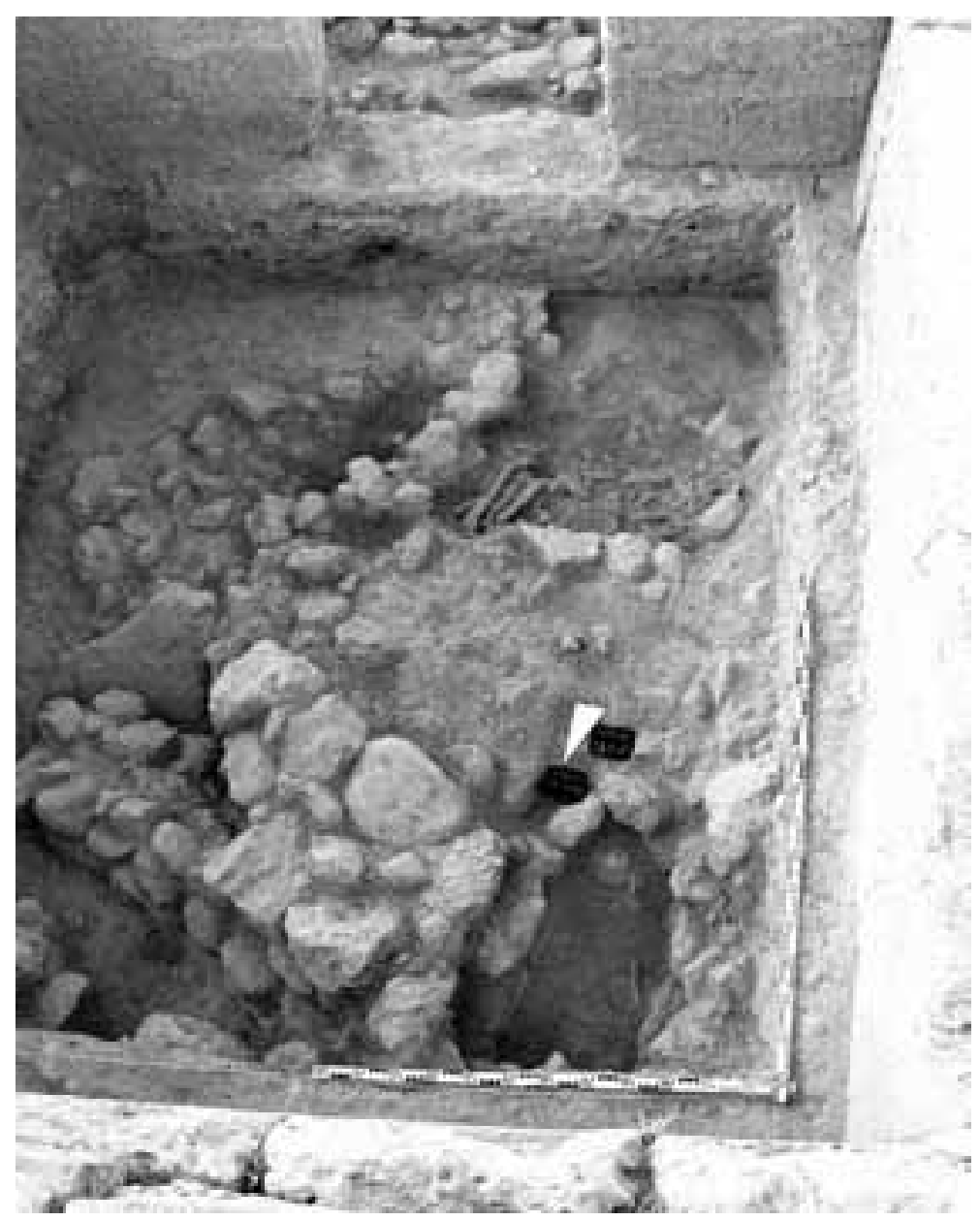

10 Ostraum. Protogeometrische Bestattungen und Steinsetzungen. Gesamtansicht von einer kleinen Steinsetzung eingefasste Grube führte von Süden her eine Rin$n{ }^{23}$. Ein über der Aschengrube auf dem Niveau der Errichtung und letzten Nutzungszeit des Südbaus befindliches Depot an Miniaturgefäßen und fragmentierten figürlichen Terrakotten bezeugt rituelle Praktiken in diesem Raum bis in das fortgeschrittene 5. Jahrhundert v. Chr. ${ }^{24}$. Etwas tiefer fand sich hier im Stratum der vorerrichtungszeitlichen Nutzung eine konzentrierte Ansammlung qualitätsvoller Keramik der ersten Hälfte des 6. Jahrhunderts v. Chr. ${ }^{25}$.

Entgegen den Befunden unter dem Kernbau und im Bereich der Kindergräber im Norden war das Aufkommen an protogeometrischer Keramik im Ostraum verschwindend gering. Die Tatsache, dass beide Bestattungen gestört waren und das Spektrum an archaischer Keramik des frühen 6. Jahrhunderts v. Chr. bis in die untersten Straten und teilweise sogar bis in die Grabschächte hinabreichte, lässt den Schluss zu, dass mit den Böden 4 und 5 durchgreifende Planierungs- und Terrassierungsmaßnahmen zu verbinden sind, die im früheren 6. Jahrhundert $\mathrm{v}$. Chr. in die Nekropole eingegriffen haben. Das bereits erwähnte, etwas höher errichtete, stelenförmige Steinmal (Abb. 8, 1)

dürfte damit im Zusammenhang stehen: Die Praxis des Versatzes von einfachen steinernen Markierungen, welche die Positionen von Gräbern und Nekropolen anzeigen sollten, ist aus Attika, der Argolis, Euböa und Naxos bekannt ${ }^{26}$.

Mit dem Steinmal und dem im Ostraum gemachten sepulkralen Gesamtbefund gelangt auch eine bauliche Besonderheit an der Nordwand des Ostraumes zu einer möglichen Erklärung, die bislang nicht befriedigend

${ }^{23}$ Zu den Rinnen M. Deoudi, Heroenkulte in homerischer Zeit, BAR International Series 806 (1999) 12 mit Vergleichen aus Eleusis und Athen; vgl. ferner u. Anm. 33.

24 s. Felten u. a. (Anm. 1:2003) 48 f. Abb. 10. 11.

25 s. Felten u. a. (Anm. 1:2003) 49. 50 Abb. 13. 14. Im errichtungszeitlichen Boden 2 des Ostraumes (+8.10 m) befindliche Fragmente eines frühattischen Gefäßes mit Gänseprozession gehören zu demselben Gefäß wie jene aus Boden 3 (+7.92 m) des Westraumes, s. Felten u. a. (Anm. 1:2003) 50 Abb. 13, 1; sie dürften bei der Errichtung des Südbaus angefallen sein.

${ }^{26}$ Zu Kyme: E. Sapouna-Sakellarakis, Geometric Kyme. The excavation at Viglatouri, Kyme, on Euboea, in: M. Bats - B. d’Agostino (Hrgs.), Euboica. L’Eubea e la presenza euboica in Calcidica e in Occidente, Atti del Convegno Internazionale di Napoli 13-16 novembre 1996 (1998) 67 mit Anm. 12; I. S. Lemos, The Protogeometric Aegean. The Archaeology of the late eleventh and tenth centuries BC (2002) 180; C. G. Styrenius, Submycenaenean studies. Examination of finds from mainland Greece with a chapter on Attic Protogeometric graves (1967) 95 Abb. 2; Kurtz - Boardman (Anm. 13) 51 Abb. 4; 56 ff., mit Verweisen auf Athen,

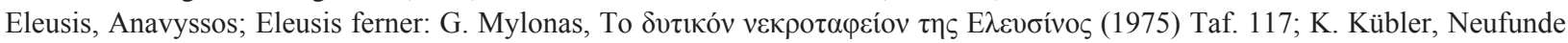
aus der Nekropole des 11. und 10. Jahrhunderts, Kerameikos IV (1943) 39, zu Grab Nr. 38; ders., Kerameikos. Ergebnisse der Ausgrabungen. Die Frühzeit, in: H. Berve (Hrgs.), Das neue Bild der Antike (1942) 35 ff. Abb. 6.; zu Eleusis: W. Kraiker K. Kübler, Die Nekropolen des 12. bis 10. Jahrhunderts, Kerameikos I (1939) 6 mit Anm. 2; 181; ferner AEphem 1898 , 86 f. Taf. 3, 4; F. Poulsen, Die Dipylongräber und die Dipylonvasen (1905) 18; allgemein Deoudi (Anm. 23$) 12$ f.; zur Argolis vgl. R. Hägg, Die Gräber der Argolis in submykenischer, protogeometrischer und geometrischer Zeit (1974) 155. 


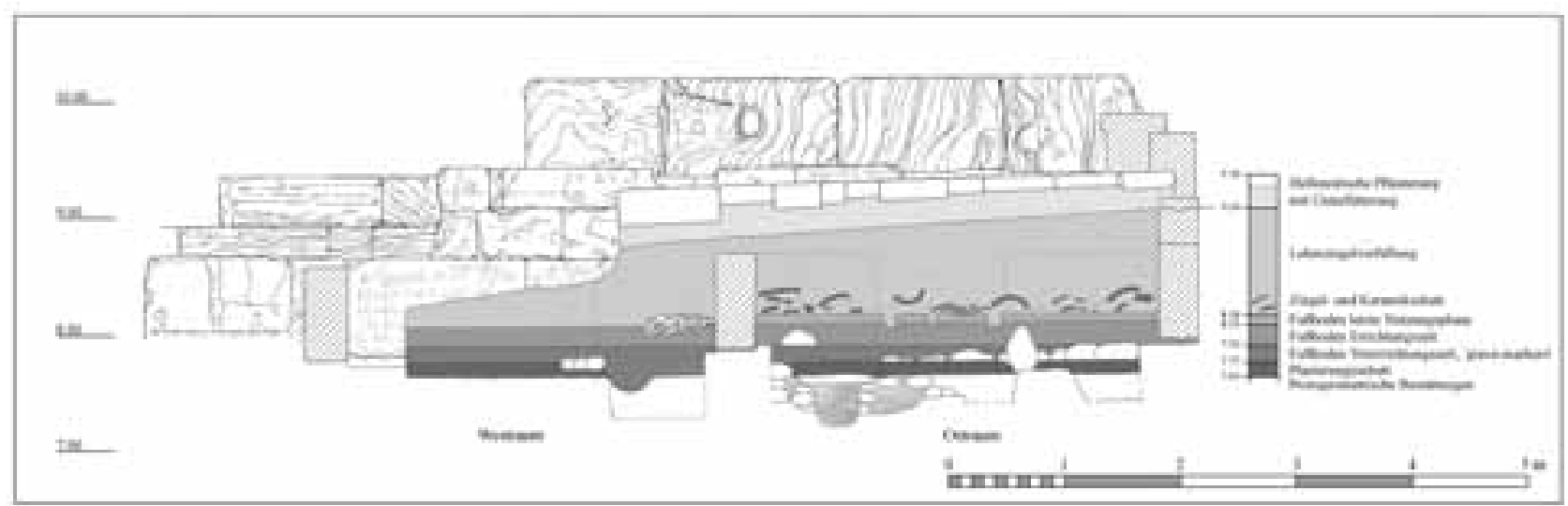

11 Ostraum. Schnittansicht mit Gesamtschema der stratigraphischen Abfolge

interpretiert werden konnte (Abb. 8, 2): Die Lagerflächen der beiden großformatigen westlichen Orthostaten an der Nordwestecke des Ostraumes weisen an ihrer Stoßfuge eckige Ausklinkungen auf, die eine rechteckige Aussparung ergeben. In diesen Hohlraum ragt von unten ein grober, hochkant versetzter Feldstein hinein ${ }^{27}$. Seine Spitze $(+8.07 \mathrm{~m})$ befindet sich auf demselben Niveau wie das bereits angeführte Steinmal im Bereich der Nordostecke. Der hochkant gestellte Stein ragte ebenso wie die zweite 'Stele' aus Boden 3 der vorerrichtungszeitlichen Lauffläche heraus und muss demnach bei der Nutzung dieses Areals im früheren 6. Jahrhundert v. Chr. noch Bedeutung besessen haben (Abb. 11). Durch die Errichtung des Südbaus im späten 6. Jahrhundert v. Chr. wurden beide Steine von Boden 2 abgedeckt, doch ist bei der Verlegung der Nordwand-Orthostaten durch unterseitiges Ausschneiden der massiven Werkstücke sorgfältig auf den Stein im Bereich der Nordwestecke Bezug genommen worden.

\section{Befundinterpretation Ostraum}

Die in den tieferen Straten von Kern- und Südbau festgestellten Teilbefunde lassen sich nun zu einem Gesamtbild zusammenfügen, das nicht nur die früheisenzeitliche Nutzung des Areals an der Westspitze von Kap Kolonna erhellt, sondern auch eine anscheinend kontinuierliche Bezugnahme auf diese bis in die Errichtungszeit und die folgenden Nutzungsphasen des Westkomplexes nachzeichnen lässt (Abb. 13). Mög-

12 Ostraum. Protogeometrischer Eisen- und Bronzeschmuck aus Grab 1 und 2

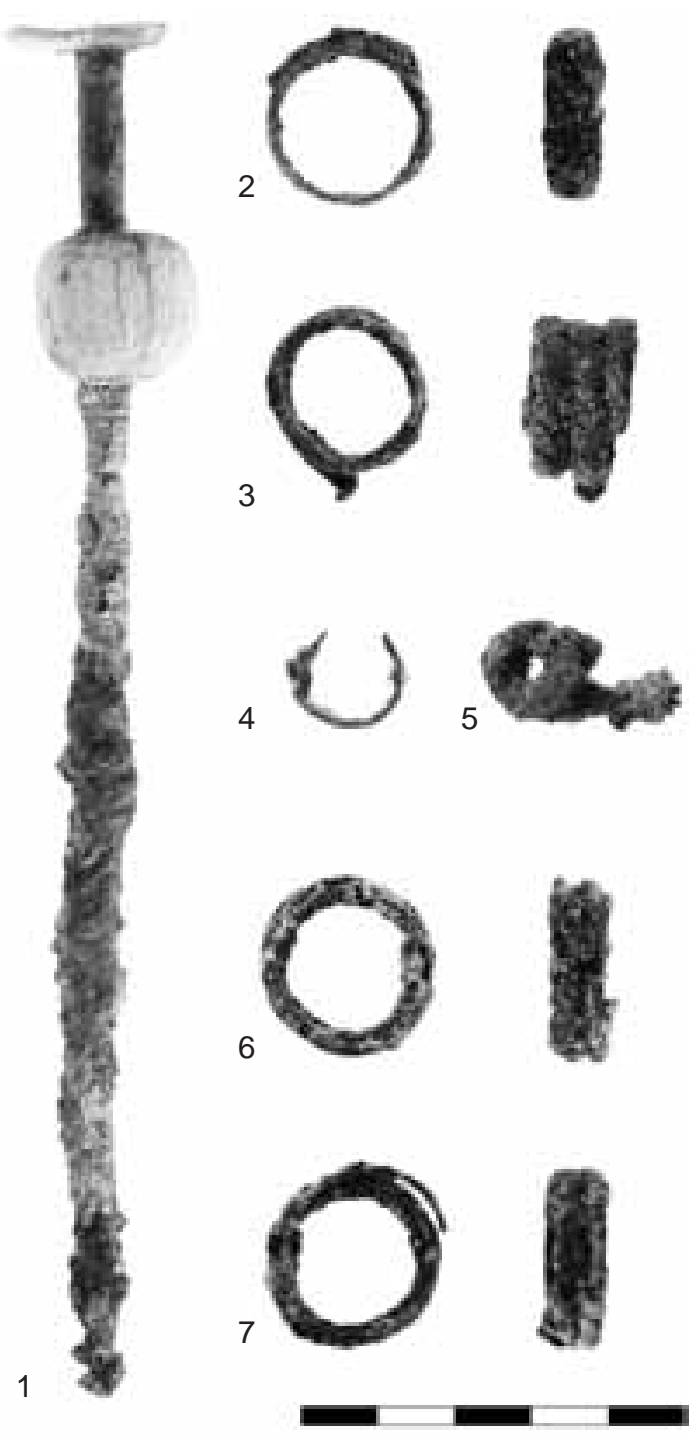

${ }^{27}$ Höhe und Unterseite dieses Steines konnten noch nicht untersucht werden, da bei der Grabung im Ostraum wandseitig ein $15 \mathrm{~cm}$ breiter Schutzsteg zur Sicherung des Mauergefüges belassen wurde. 


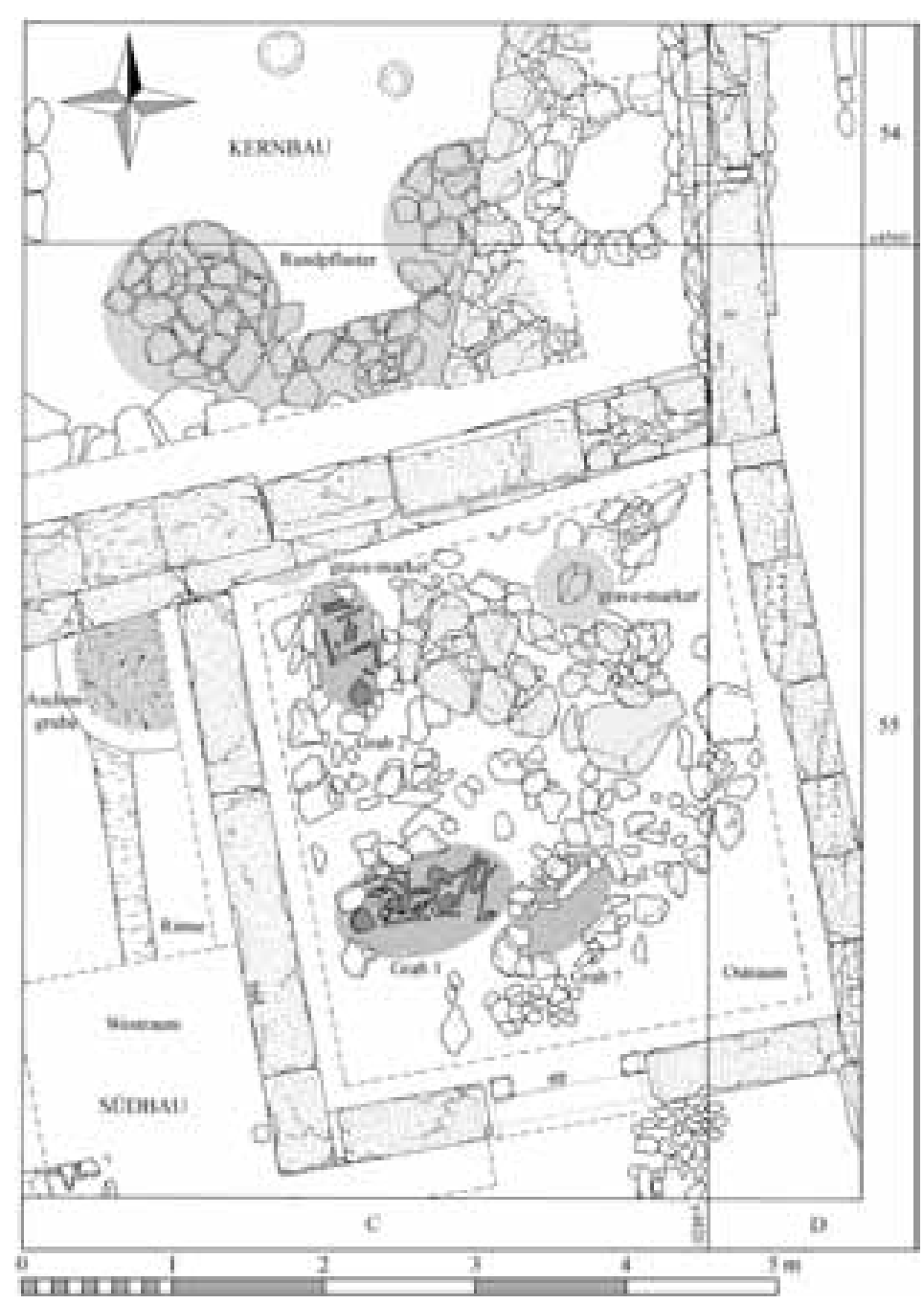

13 Südbau und Anschluss Kernbau. Bestattungen, Pflaster und Aschengrube. Detailplan des Gesamtbefundes licherweise ist hier der Beginn einer Entwicklung zu fassen, welche die funktionale Ausrichtung der Gesamtanlage des Westkomplexes bis zu seiner partiellen Verfüllung im späteren 5. Jahrhundert v. Chr. sowie seiner baulichen Revitalisierung in hellenistischer Zeit bestimmt hat ${ }^{28}$.

Nach Ausweis von Sondagenbefunden war das Areal des Westkomplexes in seinen tiefsten Lagen von einer ausgedehnten prähistorischen Bebauung okkupiert, die vor allem dem ausgehenden Mittelhelladikum und der frühmykenischen Epoche zuzuweisen ist $^{29}$. Ein Teil dieses Gebietes (Zone Südbau-Ostraum, Norderweiterung) wurde während der Frühen Eisenzeit im 10. und 9. Jahrhundert v. Chr. von Bestattungen in Anspruch genommen, wobei die Gräber stark in den älteren Baubestand eingegriffen haben. Ob die Wahl dieses Ortes für die Nekropole protogeometrischer Zeit vom Zufall, von topographischen Bedingungen oder - wie bereits für andere Orte angenommen $^{30}$ - von einer ganz bewussten Bezugnahme auf ältere 'heroische' Siedlungsreste bestimmt wurde, lässt sich noch nicht mit Sicherheit sagen. In enger Verbindung mit den Gräbern ist ein aus runden Steinpflasterungen bestehender Bezirk zu sehen (Zone Kernbau), der aufgrund vergleichbarer Befunde vermutlich rituellen Bräuchen bei den Bestattungen gedient hat ${ }^{31}$. Hierzu gehört auch eine mit Asche, Tierknochen und wenig protogeometrischer Keramik gefüllte Grube (Zone Westraum), deren Ausmaße

noch nicht festgestellt werden konnten. Die Rinne nimmt auf diese Bezug, ist jedoch später anzusetzen, da sie von einem deutlich höheren Niveau aus angelegt ist. Ein Bothros in enger Nachbarschaft zu den Bestattungen erinnert an die in der Nekyia beschriebene Praxis der Totenehrung ${ }^{32}$. Die Befunde im Ostraum und den angrenzenden Arealen zeigen aufgrund ihrer Konzentration auf einer Fläche von annähernd $25 \mathrm{~m}^{2}$ die enge räumliche Vergesellschaftung von Bestattungen und zugehörigen sepulkralen Installationen.

Die Laufflächen der Böden 4 und 5 markieren eine großflächige Umgestaltung des Areals. Hierbei erfolgte die Planierung und Einebnung der Bestattungszone, wobei auch in das Innere der Gräber eingegriffen wurde. Eine starke, nord-südlich verlaufende Böschungsmauer, die partiell die Rundpflaster unter dem Kern-

\footnotetext{
${ }^{28}$ Entscheidende Hinweise für die Gesamtinterpretation des Befundes im Ostraum und seiner Peripherie werden V. Jarosch-Reinholdt verdankt; s. ferner Felten u. a. (Anm. 1:2003) 52; Felten u. a. (Anm. 1:2004) 114.

${ }^{29}$ Wenige ältere, stark verrollte Scherben des Endneolithikums, Stufe Kephala, sowie FH-III-Ware sind Streufunde ohne baulichen oder stratigraphischen Kontext.

${ }^{30}$ So etwa P. G. Kalligas, Hero-cult in Early Iron Age Greece, in: R. Hägg - N. Marinatos - G. C. Nordquist (Hrsg.), Early Greek cult practice. Proceedings of the Fifth International Symposium at the Swedish Institute at Athens, 26-29 June, 1986 (1988) $229 \mathrm{ff}$. 233 f.; V. K. Lambrinoudakis, Veneration of ancestors in Geometric Naxos, in: ebenda $235 \mathrm{ff}$.

31 Vgl. o. Anm. 20.

${ }^{32}$ Hom. Od. 11, 25 ff.
} 
bau überdeckt und im Bereich der Nordostecke des Ostraumes ihre Fortsetzung findet, ist vielleicht in diesem Zusammenhang errichtet worden, könnte möglicherweise aber auch eine frühere Baumaßnahme repräsentieren, die noch nicht genau einzuordnen ist. Fest steht, dass ihr Bestand mit den Planierungen oberseitig auf einem Niveau belassen wurde $(+7.81 \mathrm{~m})$, welches auch der runden Steinsetzung im Westraum entspricht (+7.82 m). Diese Steinsetzung fasst ein Areal ein, welches sich genau über der unteren Aschengrube befindet. Die über der Grube angelegte, kreisförmige Einfriedung und vermutlich auch die von Süden her auf diese zulaufende Rinne zeugen somit von einer sorgfältigen Bezugnahme späterer Zeit auf die ältere Anlage ${ }^{33}$. Die vielerorts (Athen: Akademie, Kerameikos, Agora; Vari, Vourva, Marathon, Thera, Minoa-Amorgos) ${ }^{34}$ im Bereich geometrischer Nekropolen festgestellten rinnenförmigen Anlagen, auch als »offering-trenches« bezeichnet ${ }^{35}$, sind häufig spätere 'post-funeral' Installationen, dem 7. und 6. Jahrhundert v. Chr. zugehörig, und »it is ... likely that the appearance (already in the Late Geometric period) of post-funeral apparently fluid sacrifices replaced earlier libations through the marker vase ${ }^{36}$. Das Steinmal in der Nordostecke des Ostraumes und vermutlich auch der Stein unter der Nordwand sind mit den Planierungs- und Abgleichungsarbeiten zu verbinden. Sie nehmen Bezug auf die Bestattungen, wobei sie möglicherweise approximativ den Ort einer älteren, sepulkral bedeutsamen Zone markieren sollten ${ }^{37}$; diese Funktion haben die beiden 'grave-marker' noch in der ersten Hälfte des 6. Jahrhunderts v. Chr. erfüllt. Dass solche Anlagen in Ägina sogar noch viel später sichtbar und bedeutsam waren, belegt die Nennung des von einem »rohen Stein « bekrönten PhokosGrabes durch Pausanias ${ }^{38}$. Die Gestaltung des gesamten Geländes zu dieser Zeit - repräsentiert von Fußboden 3 - ist, abgesehen von der über den Hof verlaufenden, 4 m langen Pfostenreihe, noch ungeklärt. Sicher ist jedoch, dass die beiden Steine aus dem Boden herausragten und somit sichtbar die Position einer älteren Sepulkralzone angezeigt haben dürften. Bei der Errichtung des Westkomplexes am Ende des 6. Jahrhunderts v. Chr. wurde auf die Markierungen besonders geachtet. Die Stelen werden vom ersten Fußboden der Anlage abgedeckt, eine sakrale Bedeutung der Steine wird aber durch die Tatsache wahrscheinlich, dass für eine der Stelen die schweren Orthostaten der Nordwand unterseitig ausgeschnitten wurden, um deren Position bewahren zu können (Abb. 8, 2).

Diese sorgfältige Berücksichtigung eines älteren Bestandes ist mit hoher Wahrscheinlichkeit mit der funktionalen Bestimmung des gesamten Westkomplexes in Verbindung zu bringen. Die bereits von G. Welter erwogene Deutung der Anlage als kleines Phratrien-Heiligtum, welches vielleicht auf die Örtlichkeit einer älteren Toten- und Ahnenverehrung zurückgeht ${ }^{39}$, wird durch das alte und neue Fundmaterial gestützt. Hierzu gehören die Bothroi und deren omphalosförmigen Verschlusssteine, von denen bislang mindestens sieben Exemplare dem Westkomplex zugewiesen werden können ${ }^{40}$, eine Vielzahl an Miniaturgefäßen und Terrakotten, Symposiumsgeschirr, in erster Linie Skyphoi, Kantharoi und Mischgefäße, sowie Küchen- und Vorratsware, welche die Zubereitung und Konsumation von Speisen und Getränken in diesem Areal belegt. Auch dürfte es wohl kein Zufall sein, dass sich das Depot von Miniaturgefäßen und Terrakotten ${ }^{41}$ in der Nordost-

\footnotetext{
${ }_{33}$ Zu Opferrinnen und Aschengruben vgl. bereits A. Pfuhl, AM 28, 1903, 241 ff.; P. Stengel, Opferbräuche der Griechen (1910) 141 ff.; R. S. Young, Late Geometric graves and a seventh-century well, 2. Suppl. Hesperia (1939) 46 ff. 55 ff.; R. Hachmann, GGA 215, 1963, 57; K. Kübler, AA 1964, 171 ff.; M. Andronikos, Totenkult, ArchHom III, W (1968) 89 ff.; K. Kübler, Die Nekropolen des späten 8. bis frühen 6. Jahrhunderts, Kerameikos VI 1 (1959) 87. 92; G. Krause, Untersuchungen zu den ältesten Nekropolen am Eridanos in Athen, HambBeitrA 3, 1975, 132 ff.; zuletzt S. Houby-Nielsen, The archaeology of ideology in the Kerameikos. New interpretations of the 'Opferrinnen', in: R. Hägg (Hrsg.), The role of religion in the Early Greek Polis. Proceedings of the Third International Seminar on Ancient Greek cult, organized by the Swedish Institute at Athens, 16-18 October 1992 (1996) $41 \mathrm{ff}$.

${ }^{34}$ Houby-Nielsen (Anm. 33) 44 mit Anm. 16.

${ }^{35}$ Houby-Nielson (Anm. 33) $45 \mathrm{ff}$.

${ }^{36}$ Houby-Nielsen (Anm. 33) 43 f. 46.

${ }^{37}$ Kurtz - Boardman (Anm. 13) 56: »... the site of burial was remembered long after the funeral and ... had presumably been marked."

38 Paus. 2, 29, 9.

39 s. Felten u. a. (Anm. 1:2003) $41 \mathrm{f}$.

40 Sechs Exemplare bei G. Welter, AA 1932, 158 Abb. 21; ders., AA 1938, 494 Nr. 1-6 Abb. 21-23; dazu kommen ein 70 cm hoher Andesit-Omphalos und ein als Spolie im Schwellenbau verbautes Fragment, s. Felten u. a. (Anm. 1:2003) 42; Felten u. a. (Anm. 1:2004) 100.

${ }^{41}$ Vgl. o. Anm. 24.
} 
ecke des Westraumes genau über der tieferen Aschengrube befunden hat. Es zeigt, dass die Praxis ritueller Toten- bzw. Ahnenverehrung bis in die Spätzeit des Südbaus und möglicherweise darüber hinaus fortgeführt worden ist.

\section{b. Ostterrasse; Ostbau I, Ostbau 0, Oststraße}

Auf der an den Südbau anschließenden Ostterrasse konzentrierten sich die Arbeiten auf eine im Jahr 2004 zunächst nur anhand eines kleinen Mauerzuges festgestellte Architektureinheit (Ostbau I), bei der es sich nach ersten Ergebnissen 2004 um den aus zweischaligem Polygonalmauerwerk errichteten Vorgängerbau eines im Norden der Ostterrasse befindlichen, aus Rollsteinen gemauerten, einräumigen Oikos klassischer Zeitstellung handelt (Ostbau II; Abb. 1. 14. 15). Die spätere Anlage deckte mit ihrem Mauerbestand sowie den zugehörigen Fußbodenflächen den tieferen Bau ab, ferner zieht das im späteren 5. Jahrhundert v. Chr. aufgehöhte Laufniveau der Oststraße mit den gerillten Oberseiten der Ostwand des Südbaus sowie der Oberfläche der im Südbau eingebrachten Lehmziegelverfüllung gleich.

\section{Nutzungshorizont des Ostbaus II}

Die unter Ostbau II befindliche Westwand von Ostbau I konnte nach Süden auf einer Strecke von $7.5 \mathrm{~m}$ freigelegt werden (Abb. 14). Dabei zeigte sich zunächst, dass die Laufflächen des Ostbaus II die Mauern des Vorgängers zu großen Teilen verschließen. Nur an wenigen Stellen ragten einzelne Steine der erhaltenen obersten Westwandlage geringfügig aus dem späteren Fußbodenhorizont heraus und wiesen oberseitig starke Abtretungsspuren auf. Wie die mit Spurrillen versehenen Quaderoberkanten der Ostmauer des Südbaus war auch die Westwand von Ostbau I in die spätere offene Verkehrsfläche integriert worden. An wenigen Stellen sind Teile von höher anstehenden Mauerpartien des Ostbaus I in die Gestaltung des Nachfolgeareals einbezogen worden; diese an Ostbau II anschließende Fläche wurde zur Klärung der Bau- und Nutzungsphasen untersucht. Anhand der komplexen Fußbodensequenz sowie des Baubefundes zeigte sich, dass für die Anlage mehrere Nutzungsphasen zu veranschlagen sind. Gestört wird die stratigraphische Abfolge dabei durch eine Reihe von Abfallgruben, die vom Horizont des Nachfolgers Ostbau II sowie von höheren Straten aus eingetieft sind (Abb. 14).

Im inneren Bereich des Nachfolgers Ostbau II, in seinen Fußbodenstraten wie auch in mehreren nachträglich eingetieften Abfallgruben wurden bereits 2004 größere Mengen an Symposiumskeramik sowie Gebrauchs- und Küchenware festgestellt. Die Untersuchungen 2005 auf der Fläche des südlichen Anschlussareals erbrachten in den zu Ostbau II gehörigen Horizonten und in mehreren Gruben ebenfalls vermehrt Vergesellschaftungen von Terrakotten (Abb. 16) und den bekannten Keramikgattungen. Die Symposiumskeramik setzt sich aus Skyphoi, Schalen, Näpfen sowie attischen und lakonischen Krateren zusammen (Abb. 17. 18). Kochgeschirr und Vorratsamphoren (Abb. 19) runden das Spektrum des keramischen Fundmaterials aus diesem Sektor ab. Hervorzuheben sind qualitätsvolle rotfigurige Kolonettenkratere der ersten Hälfte des 5. Jahrhunderts v. Chr. (Abb. 20), von denen einer auf der Vorderseite Herakles beim Dreifußraub und auf der Rückseite einen tanzenden Jüngling zeigt (Abb. 20, 1). Ein zweites Exemplar hat die Darstellung des Dionysos mit Pferdegespann - vermutlich in Begleitung von Satyrn - zum Inhalt (Abb. 20, 3) ${ }^{42}$.

\section{Ostbau I}

Die nun auf einer Länge von 8.80 m erfasste Westwand von Ostbau I verläuft leicht geknickt. Im Süden endet sie in einem durch einen angelehnten Prellstein abgesicherten Mauereck, von dem aus die Südwand stumpfwinkelig nach Osten zieht und nach $2.90 \mathrm{~m}$ auf eine aus Polygonalmauerwerk errichtete, an der Ecke

42 Die Stücke, die an anderer Stelle von F. Felten vorgelegt und ausführlich besprochen werden, sind dem Vasenmaler Myson bzw. seinem Umkreis zuzuschreiben; vgl. die Kolonettenkratere Agrigent, Mus. Arch. Reg. R 159; R. Panvini - F. Giudice (Hrsg.), Ta Attika. Veder greco a Gela ceramiche attiche figurate dall'antica colonia (2004) 308 Nr. G 29; ARV2 241, 54 und Florenz, Antiquarium 3981; ARV22 240, 41; A. M. Esposito - G. de Tommaso, Vasi attici. Museo Archeologico Nazionale di Firenze. Antiquarium (1993) 55 Abb. 76; zu Myson allgemein: C. Vermeule, Attic red-figured column-krater. Greek work ca. 465 B.C., BMusFA 61, 1963, 112 f.; ARV² 239-242; Beazley, Paralipomena 349; J. Boardman, Athenian Red Figure Vases. The Archaic Period (1975) 112. 
mit quaderförmigen Blöcken versteifte Terrassierungsmauer trifft (Abb. 15) ${ }^{43}$. Auf der dem Rauminneren

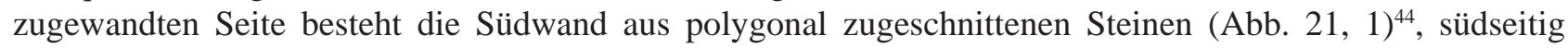
wechselt sie nach einem ca. 1 m langen Teilstück aus sorgfältigem Polygonalmauerwerk in einen Verband

14 Ostterrasse mit Ostbau I und II sowie Terrassenmauer. Gesamtansicht von Südwesten

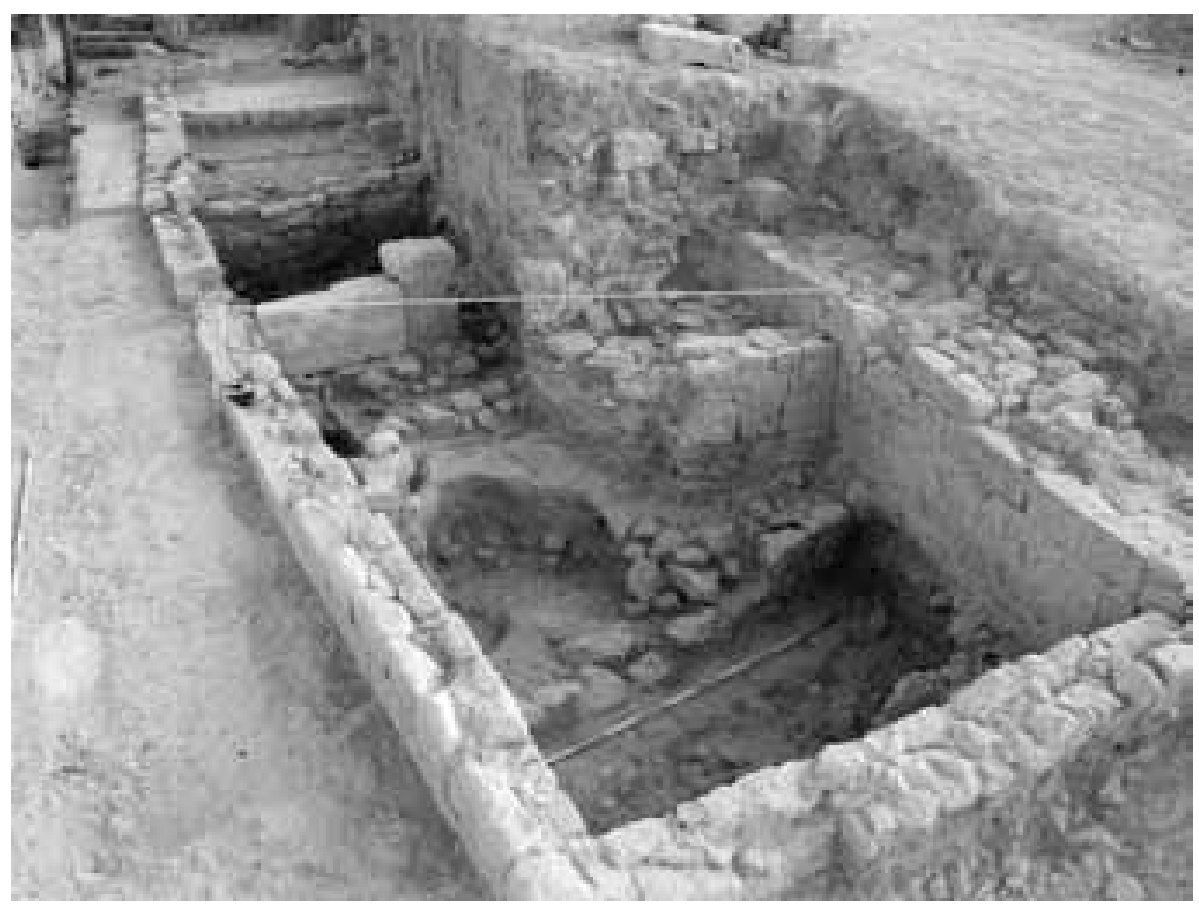

15 Ostterrasse mit Ostbau I und Oststraße. Gesamtansicht von Westen

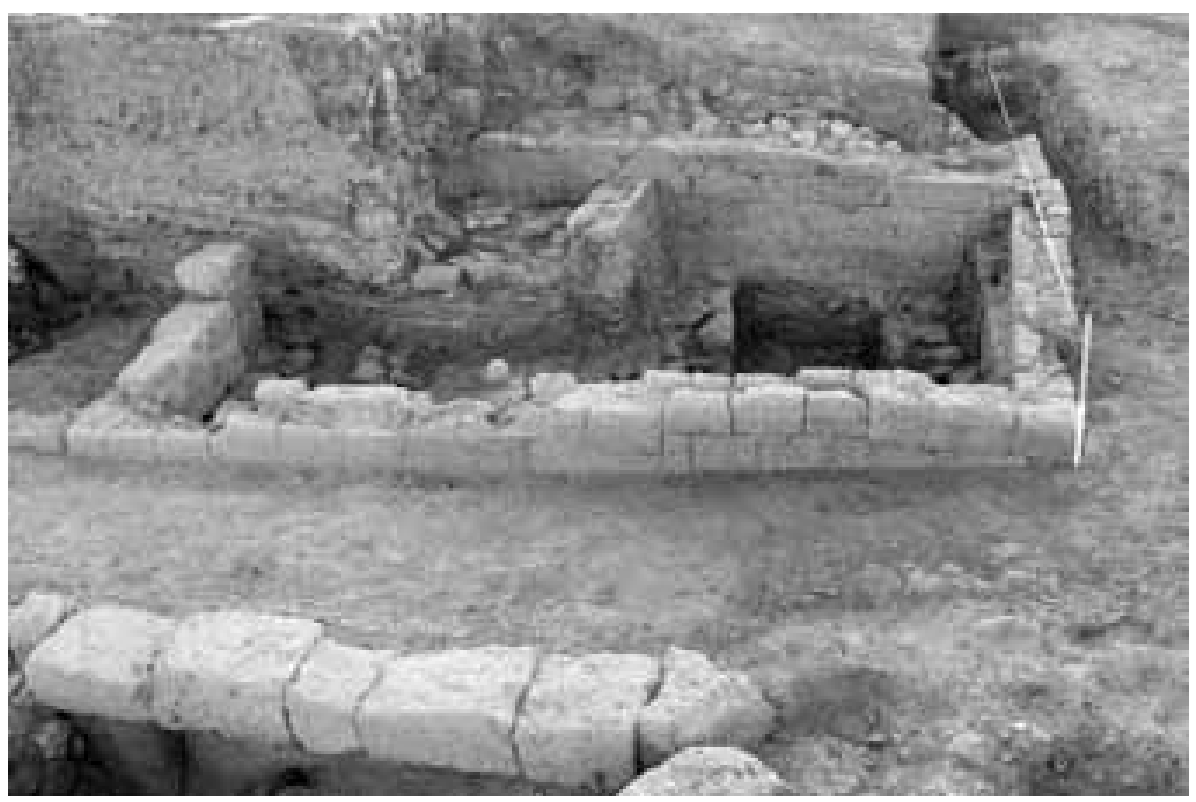

${ }^{43}$ Ein ähnlicher Verbandwechsel von Polygonalsteinen hin zu quaderförmig geschnittenen Blöcken an der Ecke begegnet in Smyrna, vgl. J. M. Cook - R. V. Nicholls, The temples of Athena (1998) Taf. 2, b.

${ }^{44}$ Vgl. Themis-Tempel von Rhamnous: A. K. Orlandos, BCH 18, 1924, 320 f. Abb. 11; B. Petrakos, Prakt 1982, 135 ff.; archaische Hofterrasse Eleusis vgl. F. Noack, Eleusis. Die baugeschichtliche Entwicklung des Heiligtums (1927) 23 Taf. 20a; ferner W. Wrede, Attische Mauern (1933) 40 ff. Abb. 7; zum polygonalen Mauerstil vgl. R. L. Scranton, Greek walls (1941) 25 ff.; F. G. Maier, Griechische Mauerbauinschriften II. Untersuchungen, Vestigia 2 (1961) 93 ff. 105 ff.; R. Martin, Manuel d'architecture grècque I. Matériaux et techniques (1965) 378 ff.; A. K. Orlandos, Les matériaux de construction et la technique architecturale des anciens Grecs II (1968) 127 ff.; F. E. Winter, Greek fortifications (1971) 80 ff.; A. W. Lawrence, Greek aims in fortification (1979) 235 ff.; J. P. Adam, L’architecture militaire grècque (1982) 23 ff; T. Marksteiner, Die befestigte Siedlung von Limyra. Studien zur vorrömischen Wehrarchitektur und Siedlungsentwicklung in Lykien unter besonderer Berücksichtigung der klassischen Periode (1997) 123 f. mit Anm. 20. 

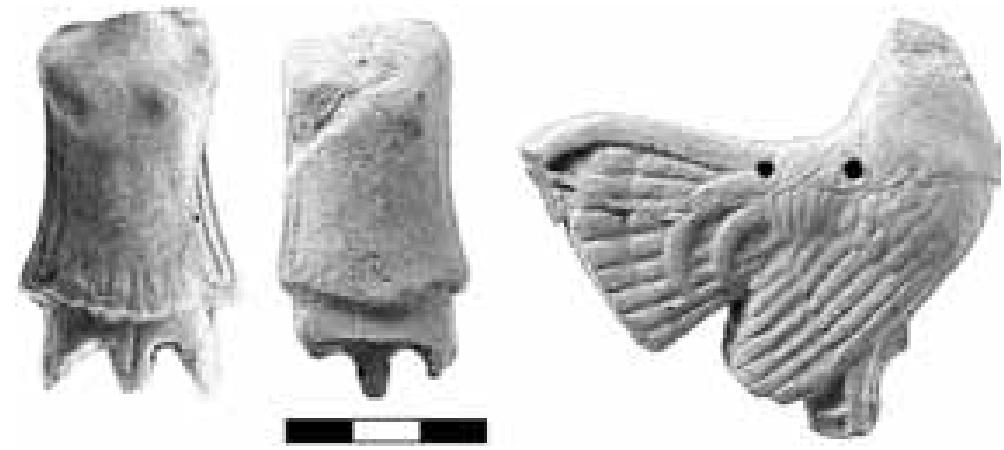

16 Ostterrasse. Areal Ostbau I. Terrakotten aus den Nutzungszeit von Ostbau II

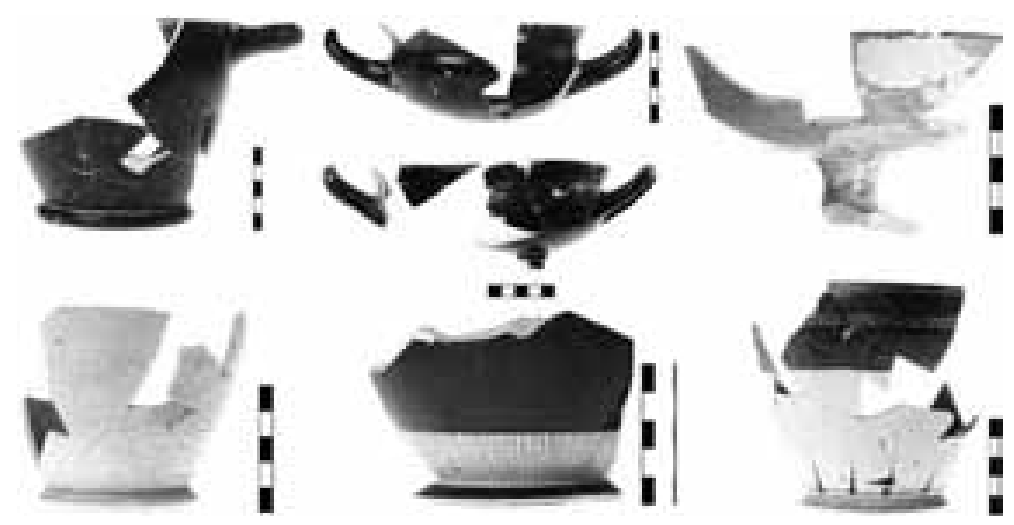

17 Ostterrasse. Areal Ostbau I. Skyphoi und Schalen aus dem Vorplatz von Ostbau II. Auswahl aus kleinteiligem Rollsteinmaterial grober Zurichtung (Abb. 2). Die innen mit kleinen bis mittelgroßen Rollsteinen verfüllte Terrassenmauer formt am Treffpunkt mit der Südwand eine spitzwinkelige Ecke und verläuft in der Folge nach Norden und Osten.

Aufgrund der Mauerführung an der Südwestecke und des Ansatzes an die Terrassenmauer erhält Ostbau I einen stark trapezoiden Grundriss (Abb. 1. 15); die Anlage setzt westseitig an die Terrassenmauer an. Die schräge, außenseitig vorwiegend grob gemauerte Südwand hat in ihren unteren Lagen als Analemma einer im Süden vorbeiführenden Straße gedient, wobei ihr südseitig sorgfältig gemauertes Teilstück im Anschluss an die Südwestecke auf eine frühere Phase bei tieferem Straßenniveau deuten könnte. Im Inneren von Ostbau I verlaufen zwei Quermauern, die den Baukörper in mindestens drei Raumkompartimente aufteilen. Der erhaltene Rest der nördlichen Quermauer besteht aus massivem, möglicherweise wiederverwendetem Orthostatenwerk (Abb. 14), die südliche, durch einen eingetieften, späten Bothros nur noch anhand kurzer Stümpfe fassbare

Querwand entspricht in ihrer Polygonaltechnik der Süd- und Westwand. Die nördliche Ausdehnung von Ostbau I ist aufgrund der Überbauung durch Ostbau II noch nicht klar zu fassen. Ein unter dessen Innenfußboden freigelegter, kurzer Mauerstumpf aus Polygonalmauerwerk ließe bei seiner Verbindung mit der Westwand die Gesamtlänge der Anlage auf $12.15 \mathrm{~m}$ veranschlagen. In der Westwand befindet sich eine $0.70 \mathrm{~m}$ breite Türöffnung mit Angelloch und einer aus mittelgroßen Platten verlegten Schwelle (+8.79 m).

\section{Bautypus des Ostbaus I}

Ostbau I repräsentiert mit seinen durch die bisherigen Grabungen festgestellten baulichen Strukturen den Typus des mehrräumigen Oikos, eines Gebäudes mit einem durch mehrere Kammereinheiten parataktisch gegliederten Innenraum. Der Grundriss ist nicht streng orthogonal, sondern bildet ein langgestrecktes Trapez mit schräg verlaufenden Innenmauern, von denen eine mit einer ausmittig angeordneten Türöffnung ausgestattet ist. Die Anlage wird im Osten von der nord-südlich verlaufenden Terrassenmauer abgeschlossen, welche das höher gelegene, östliche Gelände abstützt. Erweckt der Bau durch seinen nicht geradlinig geführten Mauerverlauf zunächst den Eindruck einer flüchtigen Errichtung, so erlauben seine sorgfältige Polygonalbauweise und die unmittelbare Nähe zum Südbau doch, eine bedeutende Anlage zu rekonstruieren. Darüber hinaus kann Ostbau I formal mit einer kleinen Gruppe von hoch- bis spätarchaischen langgestreckten, mehrräumigen Oikoi in Verbindung gebracht werden, die in Heiligtümern oder kleinen Sakralbezirken auftreten. Hierzu gehört ein im Heroon von Eretria in unmittelbarer Umgebung geometrischer Bestattungen errichteter $\mathrm{Bau}^{45}$ mit fünf parataktisch gestaffelten Kammern aus dem 7. Jahrhundert v. Chr., der als Gebäude für kulti-

${ }^{45}$ K. Schefold, Die Grabungen in Eretria im Herbst 1964 und 1965, AntK 9, 1966, 120 ff.; K. Schefold - D. Knoepfler, Forschungen in Eretria 1974 und 1975, AntK 19, 1976, 53 ff.; C. Bérard, L’Hérôon à la Porte de l'Quest, Eretria III (1970) 56 ff.; ders., 
sche Versammlungen und Bankette gedeutet wird $^{46}$ und um die Mitte des 6. Jahrhunderts v. Chr. einen Nachfolger erhalten hatte. Ein ähnlicher langgestreckter Mehrraumoikos, vermutlich ebenfalls ein Banketthaus, befindet sich im Archegésion auf Delos ${ }^{47}$ : Der im ausgehenden 7. Jahrhundert v. Chr. angelegte $\mathrm{Bau}^{48}$ besaß zunächst vier Räume und wurde um die Mitte des 6. Jahrhunderts v. Chr. durch Anbauten an beiden Schmalseiten erweitert. Analogien zum Befund im Westkomplex von Kolonna weist schließlich auch Bau Q in Kommos auf ${ }^{49}$, eine im späten 7. Jahrhundert v. Chr. vor einer Stützmauer errichtete, aus fünf oder sechs Räumen ${ }^{50}$ bestehende Anlage $^{51}$.

Aufgrund der Überbauung und der spä-
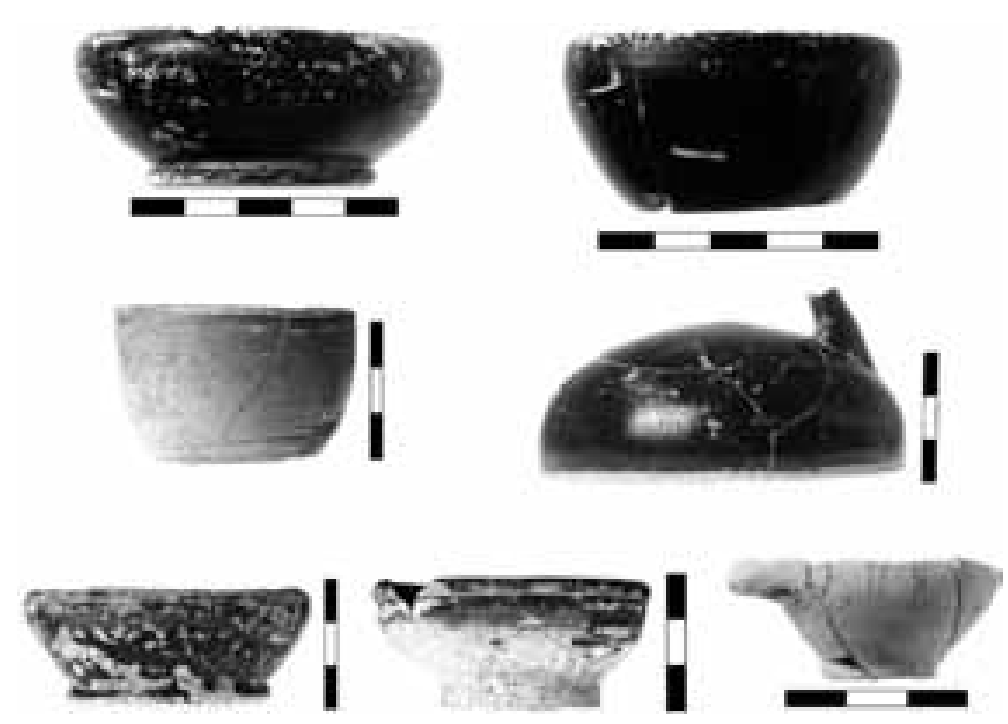

18 Ostterrasse. Areal Ostbau I. Näpfe, Miniaturskyphos und Askos, Ostbau II. Auswahl teren Gruben ließen sich nur an wenigen Stellen Reste eines zu Ostbau I gehörigen Fußbodens nachweisen $(+8.80 \mathrm{~m})$. Die in dessen Füllung befindliche, stark zerscherbte Keramik des späteren 6. Jahrhunderts v. Chr. ist gegenüber den Befunden an Symposiumskeramik des Nachfolgers Ostbau II quantitativ geringer vertreten (Abb. 20, 3), sie weist aber mit ihrem Spektrum - Skyphoi, Schalen, Mischgefäße und Küchenware - in einen ähnlichen funktionalen Zusammenhang.

Nach der Errichtung von Ostbau II und dem Verschluss seines Vorgängers diente das betreffende Gelände als freier Vorplatz. Ostseitig blieb es weiterhin von der Terrassenmauer abgeschlossen, wobei der verbliebene Reststumpf der südlichen Querwand von Ostbau I als Abschluss für eine podestartig gestufte Pflasterung genutzt wurde. Auch die Südwand blieb mit ihrem Ansatz an die Terrassenmauer weiterhin als Begrenzung für das aufgehöhte Straßenniveau in Verwendung.

Topographie et urbanisme de l'Erétrie archaïque: L’Hérôon, Eretria VI (1978) 89 ff.; P. Auberson - K. Schefold, Führer durch Eretria (1972) 79 f.; Deoudi (Anm. 23) 77 f.

${ }^{46}$ Die Länge von 15 m spricht dafür, dass das Maß eines halben Hekatompedos zugrundeliegt, was nach A. Kalpaxis wiederum für ein Kultgebäude spricht: A. Kalpaxis, Früharchaische Baukunst in Griechenland und Kleinasien (1976) 71; vgl. Auberson - Schefold (Anm. 45) 79; G. Ekroth, Altars in Greek Hero-Cults. A Review of the Archaeological Evidence, in: R. Hägg (Hrsg.), Ancient Greek Cult Practice from the Archaeological Evidence. Proceedings of the Fourth International Seminar on Ancient Greek Cult, Swedish Institute at Athens 1993 (1998) 128.

${ }^{47}$ F. Robert, Thymélè (1939) 189 f.; ders., Le sanctuaire de l'archégète Anios à Délos, RA 41, 1953, 13 ff.; H. Gallet de Santerre, Délos primitive et archaique (1958) 268 ff.; G. Daux, BCH 86, 1962, 959 ff.; ders., BCH 87, 1963, 862 ff.; R. Vallois, L’architecture hellénique et hellénistique à Délos I (1966) 70 ff.; P. Bruneau, Recherches sur les cultes de Délos à l'époque hellénistique et à l'époque impériale (1970) 420 ff.; Deoudi (Anm. 23) 76 f.; vgl. G. Kuhn, Untersuchungen zur Funktion der Säulenhalle in archaischer und klassischer Zeit, JdI 100, 1985, 227 ff.

${ }^{48} \mathrm{Im}$ 2. Jh. v. Chr. wurde das Temenos unter Beibehaltung des Grundrisses vergrößert und erhielt ein Plattenpflaster. Trotz baulicher Unterschiede zeigt auch im Westkomplex von Ägina die hellenistische Neukonzeption deutliche strukturelle Analogien mit den Vorgängerbauten, s. Felten u. a. (Anm. 1:2003) 43 ff.

49 J. W. Shaw, The Architecture of the Temples and Other Buildings, in: ders. - M. C. Shaw (Hrsg.), Kommos IV 1. The Greek Sanctuary, 1 (2000) $31 \mathrm{ff}$.

${ }^{50}$ Die ausmittigen Türöffnungen beruhen offenbar auf einer möglichst optimalen Innenraumnutzung, J. W. Shaw in: Shaw - Shaw (Anm. 49) 34.

${ }^{51}$ Möglicherweise hat der Bau eine Vorhalle besessen, J. W. Shaw in: Shaw - Shaw (Anm. 49) 32. Ob Bau Q eine sakrale Funktion hatte, ist nicht ganz klar. Die vielen Amphorenfragmente lassen an einen Nutzbau zur Lagerung denken; A. W. Johnston, Pottery from Archaic Building Q at Kommos, Hesperia 62, 1993, 339 ff. 


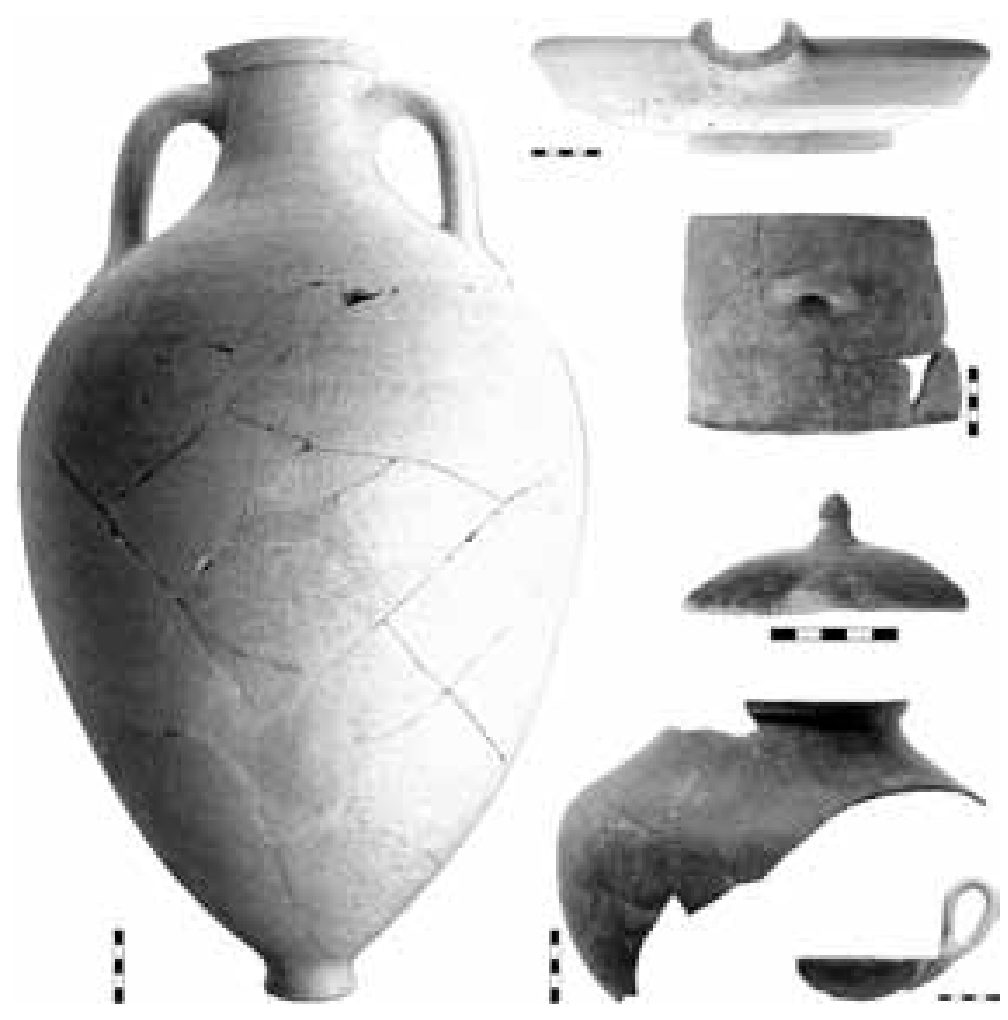

19 Ostterrasse. Areal Ostbau I. Amphore und Küchenware, Ostbau II. Auswahl
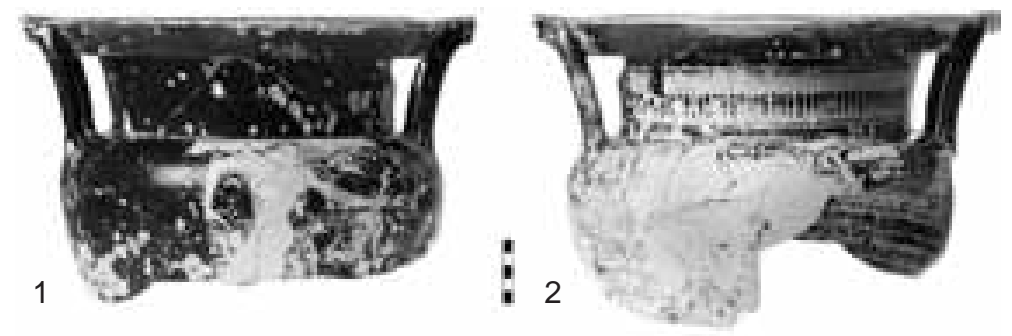

3
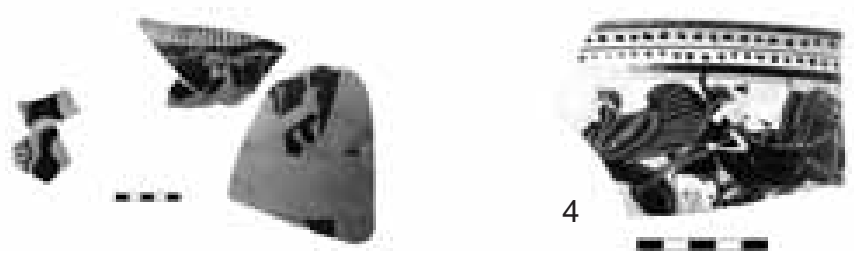

20 Ostterrasse. Areal Ostbau I. Rotfiguriger Krater des Myson (1-2), weitere Kraterfragmente aus Nutzungszeit Ostbau II (3) sowie Skyphosfragment der CHC-Gruppe (4)

\section{Ostbau 0}

Bei den tieferen Untersuchungen im Bereich von Ostbau I hat sich gezeigt, dass dessen Mauern ihrerseits eine weitere Struktur überdecken, die ein anderes bauliches Bild bietet. Die in Polygonalbauweise errichteten Wände von Ostbau I sitzen auf einem $0.65 \mathrm{~m}$ (Südwand) und $0.30 \mathrm{~m}$ (Westwand) hohen Mauersockel aus mittelgroßem und dicht gefügtem, bei klaffenden Fugen mit kleinsteinigem Material ausgezwicktem Bruchsteinwerk

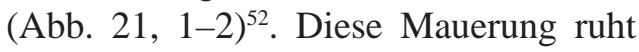
unter der Westwand auf einer $0.25 \mathrm{~m}$ hohen, ostseitig um $0.10-0.15 \mathrm{~m}$ vorkragenden Fundamentschicht aus mittelgroßen, flachen Rollsteinen ${ }^{53}$. Die Oberkante der Mauern vollführt zwischen West- und Südwand einen übergangslosen, $0.25 \mathrm{~m}$ hohen Sichtsprung. Während an der westlichen Langseite (Abb. 21, 2) die Mauer oberseitig unregelmäßig endet und die polygonalen Blöcke von Ostbau I mit ihren Lagerflächen darauf Bezug nehmen, besitzt die untere Südwand (Abb. 21, 1) ein geradliniges, horizontales Auflager, auf dem durch die Verlegung flacher Steine eine zusätzlich abgeglichene Lagerfläche für die schräg versetzte Südwand von Ostbau I hergestellt wurde. Im Gegensatz zur stumpfwinkeligen Führung der Polygonalmauer an der Südwestecke von Ostbau I bilden die Mauern von Ostbau 0 einen rechten Winkel. An der Kontaktstelle seiner Südwand mit der Terrassenmauer zeigt eine Baunaht, dass der Mauerverband ursprünglich weiter nach Osten verlief (Abb. 15).

Das untere Bruchsteinmauerwerk gehört zu einem Vorgänger von Ostbau I, der sich auch an zwei weiteren Stellen feststellen ließ. Die schräg geführte, südliche Zwischenwand von Ostbau I sitzt ebenfalls auf einer unteren Bruchsteinwand, von der sich die westlichen und östlichen Ansätze erhalten haben, welche mit der unteren Westwand einen rechten Winkel bilden. Ferner wurde nördlich der ersten Querwand von Ostbau I ein 2.20 m langer, ost-westlich verlaufender Mauerzug aus Bruchstein frei-

\footnotetext{
${ }^{52}$ Vgl. E. Akurgal, Alt-Smyrna I (1983) Taf. 28b; 29b; 33a; R. Senff, AA 1995, 209 Abb. 11; ähnliche Bautechnik an dem Vorgänger des alten Bouleuterions auf der Athener Agora, vgl. H. A. Thompson, The Tholos of Athens and its Predecessors, 4. Suppl. Hesperia (1940) 8 ff.; F. Lang, Archaische Siedlungen in Griechenland (1996) $153 \mathrm{f}$.

${ }^{53}$ Einen ähnlichen Verbandwechsel weist die Ostwand des sog. Priesterhauses in Smyrna auf, vgl. Cook - Nicholls (Anm. 43) Taf. 7b.
} 
gelegt, der mit dem Ober- und Unterkantenniveau der Mauerzüge unter Süd- und Westwand von Ostbau I gleichzieht und wiederum mit der unteren Westwand einen rechten Winkel bildet. Dieser Mauerzug gehört möglicherweise zur Nordwand des Vorgängers von Ostbau I.

Nach dem bisher freigelegten Baubestand lässt sich für Ostbau 0 ein zweiräumiger, ca. $7 \mathrm{~m}$ langer Oikos mit trapezoidem Grundriss veranschlagen, dessen ostseitige Ausdehnung durch die sekundär errichtete Terrassenmauer derzeit noch nicht zu fassen ist.

Im Inneren von Ostbau I, dessen Süd- und Westwand den Mauerbestand von Ostbau 0 weitgehend mitverwenden, ließen sich trotz der durch Ostbau II und in späterer Zeit eingetieften Grubenstörungen zwei Fußböden $(+8.60,+8.53 \mathrm{~m})$ sowie ein Bothros identifizieren, die mit dem ältesten Vorgänger zu verbinden sind. Das Fundmaterial aus den betreffenden Laufflächen besteht - abgesehen von früheren Einsprengseln - vor allem aus archaischer Keramik, deren chronologisches Spektrum nicht über die Mitte des 6. Jahrhunderts v. Chr. hinunterreicht (Abb. 22, 1). Damit ergibt sich für Ostbau 0 ein zeitlicher Horizont, der mit dem hocharchaischen Stratum unter dem Südbau - repräsentiert durch Boden 3 (+7.92 m) - identisch sein dürfte. Mit Ostbau 0 ist zusätzlich zu der im Hof des Südbaus aufgedeckten Pfostenstellung eine weitere Architektureinheit fassbar, von welcher das Areal vor der Errichtung der massiven Orthostatenstrukturen spätarchaischer Zeit eingenommen worden war. Durch ihre Ausrichtung lassen sich die Pfostenstruktur und die vermutete Nordmauer von Ostbau 0 möglicherweise auch baulich miteinander verbinden.

Neben der Westmauer und im Anschluss an die Nordmauer von Ostbau 0 wurden zwei mit Steinplatten eingefasste bzw. abgedeckte Bestattungen festgestellt, deren Belegungen gänzlich entfernt oder stark gestört waren (Abb. 1). Das südliche Grab (Grab 4), das unmittelbar an die Westwand von Ostbau 0 anschließt, erwies sich als mit einer Steinplatte nachträglich abgedeckt. Daneben befindliche Reste eines großen protoattischen Gefäßes (Abb. 22, 2) gehören möglicherweise zu den ursprünglichen Beigaben. Das nördliche, beigabenlose Grab (Grab 3) mit sekundär verschobener Deckplatte enthielt Reste von zwei übereinanderliegenden Skeletten, von denen sich das obere stark aus seiner

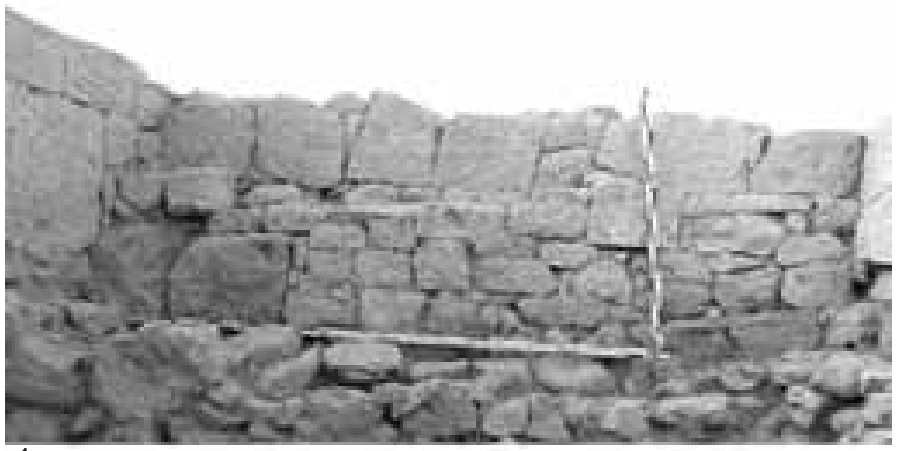

1

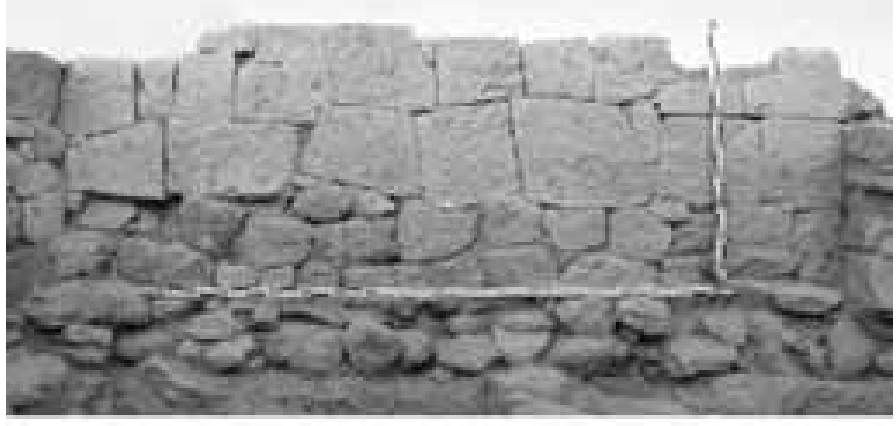

2

21 Ostterrasse. Südwand (1) und Westwand (2) von Ostbau 0 mit aufsitzendem Polygonalmauerwerk von Ostbau I. Ansichten von Norden und Osten
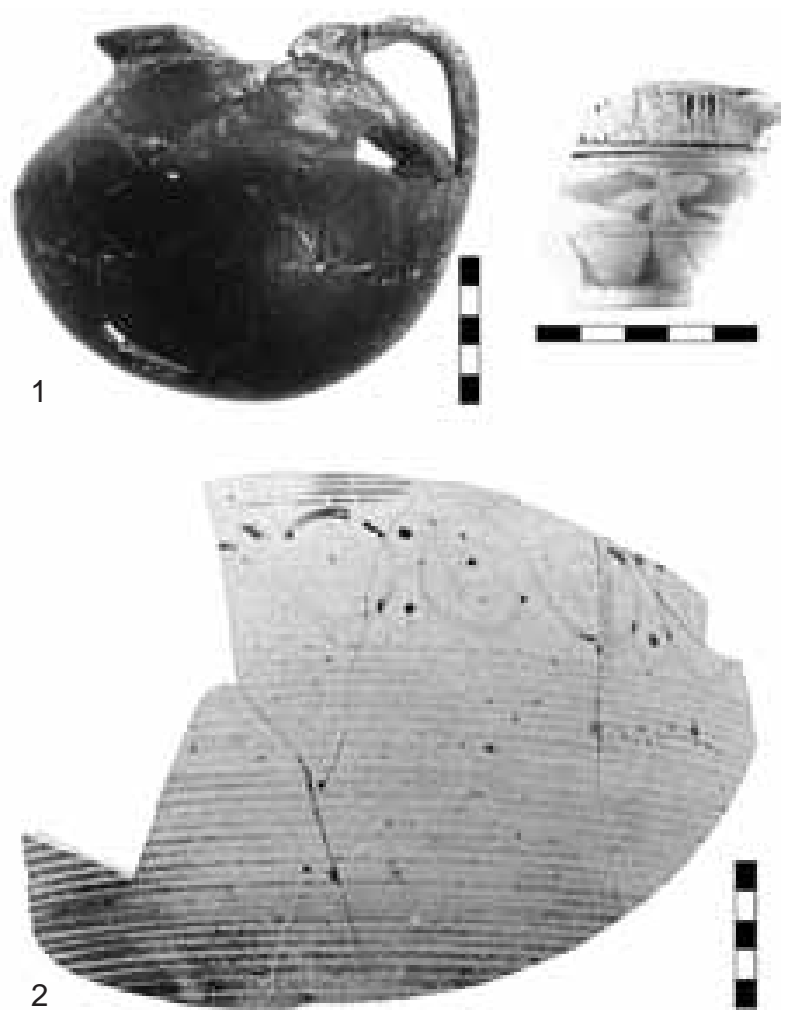

22 Ostterrasse. Ostbau 0. Keramik aus Bothros und Fußboden (1). Protoattisches Gefäßfragment (2) 

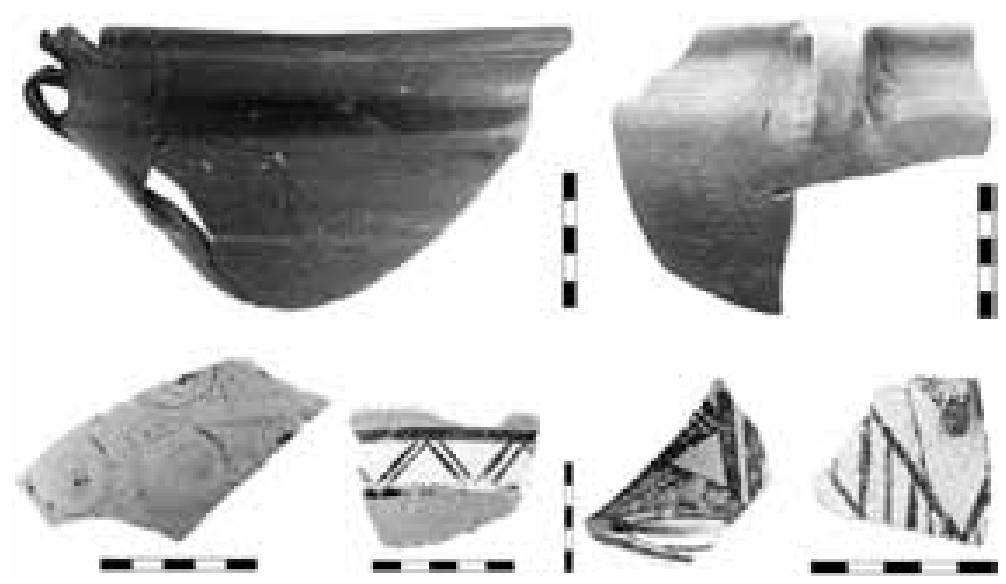

23 Ostterrasse. Areal Ostbau 0. Mittelhelladische und frühmykenische Keramik. Auswahl

ursprünglichen Lage verräumt erwies. Der sekundäre Eingriff in die Gräber dürfte mit der Errichtung von Ostbau 0 in Verbindung zu bringen sein. Es liegt nahe, diese Gräber in Zusammenhang mit den Bestattungen unter dem Ostraum des Südbaus zu sehen, auch wenn sie auf höherem Niveau liegen.

Die Unterkanten der Mauern von Ostbau 0 greifen bereits in die prähistorischen Siedlungsschichten unter dem Westkomplex ein. Dabei handelt es sich um drei ost-westlich verlaufende, parallel geführte Mauerzüge, auf denen die Mauern von Ostbau 0 sowie die ostseitige Terrassenmauer direkt aufsitzen. Das keramische Fundmaterial aus dem Bereich der beiden südlichen Mauerzüge weist in die entwickelte Mittelbronzezeit, dasjenige der Straten im Anschluss an die Nordmauer von Ostbau 0 gehört bereits der frühmykenischen Epoche an (Abb. 23). Gemeinsam mit den bereits 2004 freigelegten Befunden im Hofareal des Südbaus sowie innerhalb und nördlich des Ostbaus II ergibt sich für das 2. Jahrtausend v. Chr. das Bild einer ausgedehnten prähistorischen Bebauung, welche die Westspitze von Kap Kolonna in Gestalt einer terrassenförmig angelegten Hangsiedlung eingenommen hat.

\section{Oststraße}

Zur Klärung der Laufflächenabfolge und deren Verhältnis zu den gebauten Strukturen von Südbau und Ostbau 0, I sowie II wurden im Bereich der Oststraße an zwei Stellen Sondagen angelegt. Der oberste Boden (+9.08 m), der mit den Spurrillenquadern der Ostmauer des Südbaus sowie dessen Lehmziegelverfüllung gleichzieht, gehört zu einer entwickelten Nutzungszeit von Ostbau II, als dieser nach der Auflassung des Südbaus eine nunmehr offene Verkehrsfläche nach Osten hin abschloss. Gleiches gilt für eine unter Boden +9.08 verlaufende Straßenfläche (+9.00 m). Die Keramik aus der Füllung der oberen Böden datiert in die zweite Hälfte des 5. Jahrhunderts v. Chr. und entspricht einem chronologischen Horizont, welcher der Verfüllung des Südbaus gleichzusetzen ist. Das angeführte keramische Fundmaterial aus den Böden und den zugehörigen Bothroi von Ostbau II belegt indessen, dass für die Anlage bereits eine frühklassische Phase zu veranschlagen ist. Hieraus kann gefolgert werden, dass Ostbau II und Südbau eine gewisse Zeit gleichzeitig nebeneinander bestanden haben. Zu dieser frühen Phase von Ostbau II gehört eine tiefer liegende Straßenfläche (+8.94 m), deren Aufschüttung im südlichen Abschnitt der Oststraße im Jahr 2004 untersucht worden ist. Die untere Straße geht westseitig mit einer kräftigen Wölbung in einen zwischen Ostbau II und Südbau verlaufenden, ostseitig mit hochkant gestellten Steinplatten begrenzten Kanal über. Der Kanal verläuft in einer tieferen Straßenfläche (+8.70 m), die mit Ostbau I und dessen Schwellenniveau (+8.79 m) zu verbinden ist. Als Kanalsohle dient eine weitere, hart getretene Lauffläche $(+8.46 \mathrm{~m})$, die nach Westen unter den Kanalsteinen hindurchzieht. Aufgrund ihres Niveaus kann diese unterste Straßenfläche nur zu Ostbau 0 gehört haben, da sie die Lagerfläche (+8.54 m) der Polygonalmauern von Ostbau I unterläuft. Die Steinsetzung des Kanals war nur an der östlichen Langseite zu fassen, möglicherweise sind seine westliche Mauerung sowie die anschließenden Straßenflächen bei späteren Umbauarbeiten für den Südbau entfernt worden.

\section{c. Südlicher Anschluss Westkomplex; Ost-West-Straße, Diateichisma}

Unmittelbar südlich des Ostbaus I wurde eine großflächige Sondage angelegt, um Aufschlüsse über das Südende des Westkomplexes sowie die Topographie und bauliche Gestaltung des angrenzenden Areals zu erhalten. Hier zeigte sich bereits knapp unter der modernen Geländeoberfläche die zementharte Lauffläche einer $2.75 \mathrm{~m}$ breiten, ostseitig ansteigenden Straße (Abb. 24). Ihr auffallend dicker Belag besteht aus mehre- 
ren, offenbar über längere Zeit ständig mit verschiedenen Lagen aus kiesel- und splittversetztem Estrich aufgehöhten Schichten. Die Straße fällt nach Westen hin $a b$ und trifft auf den bereits freigelegten Abschnitt der Südstraße ${ }^{54}$. Die außenseitig grob hergerichtete Südmauer von Ostbau I bindet mit dem Belag ab, desgleichen verschließt die Straße die sorgfältig gebaute südliche Sichtseite der Terrassenmauer, deren bossierter Bodenstreifen ( $\mathrm{OK}+8.95 \mathrm{~m}$ ) im Zusammenhang mit einer tiefer liegenden, älteren

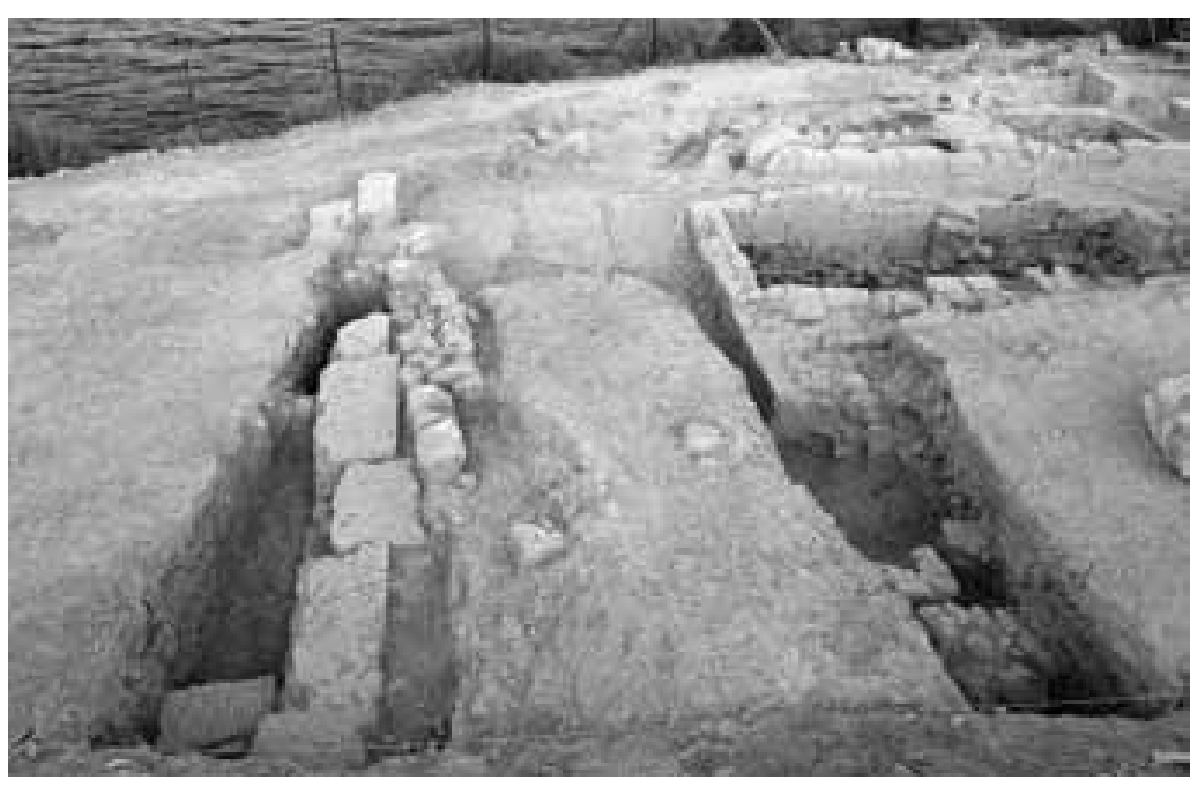

24 Südlicher Anschluss Westkomplex. Ost-West-Straße und hellenistisches Diateichisma mit Eingang. Ansicht von Osten Straßenoberfläche zu sehen ist. In der nördlichen Hälfte der Grabungsfläche reißt der Straßenbelag aufgrund tief reichender Störungen durch die byzantinische Bebauung ab. Auch auf dem Straßenrand an der gegenüberliegenden Seite ist das Fundament eines byzantinischen Gebäudes in den Belag eingetieft.

Am südlichen Abschluss der Straße wurde ein Mauerzug aus großen, bis zu $1.40 \mathrm{~m}$ langen und $0.65 \mathrm{~m}$ breiten, möglicherweise wiederverwendeten Porosquadern freigelegt. Den unteren Abschluss der Läuferkonstruktion bildet eine grobsteinige Rollierung $(\mathrm{OK}+8.53 \mathrm{~m})$. Die z. T. mit Verschubmarken versehenen Quader sind in ihren Stoßfugen leicht gegeneinander versetzt, ihr Auflager verläuft trotz kleinerer Versprünge über die bisher erfasste Länge von $8.5 \mathrm{~m}$ auf selbem Niveau (+9.19 m). Die Mauer ist an mehreren Stellen ausgerissen. Ein südseitig gebrochener Block erweckt den Eindruck eines binderartigen Einschubes, auch eine Mauerverbreiterung am östlichen Ende der Grabungsfläche könnte darauf hindeuten, dass die Struktur ursprünglich breiter war. Damit entspräche die Mauer dann dem Rest eines Diateichismas, das bereits früher an einer anderen Stelle in einer Entfernung von 117 m südlich des Apollon-Tempels freigelegt worden ist. Bei dieser Mauer handelt es sich um den Bestandteil eines umfangreichen Bauprogramms, welches im Zusammenhang mit der pergamenischen Neugestaltung des Kolonna-Hügels im späteren 3. Jahrhundert v. Chr. zu sehen ist ${ }^{55}$. Unterstrichen wird die chronologische Stellung der Mauer durch das Fundmaterial einer kleinen Testsondage am Ostende des Verbandes, das ausschließlich aus hellenistischer Keramik besteht. Den durch die Grabung erfassten westlichen Abschluss des Mauerzuges bilden zwei große, mit Spurrillen versehene Schwellblöcke, die einen mindestens 2.10 m breiten Zugang zum Westkomplex belegen ${ }^{56}$. Die möglicherweise als Torbau zu rekonstruierende Struktur führt dabei genau in den Kreuzungspunkt der drei im Bereich des Westkomplexes festgestellten Straßen. Diese Position des Torbaus unterstreicht die Bedeutung des Westkomplexes, der - wie sich bereits in früheren Untersuchungen gezeigt hat - auch in seinem inneren Gefüge Bestandteil der durchgreifenden hellenistischen Neugestaltung auf der Akropolis von Ägina gewesen ist ${ }^{57}$.

\footnotetext{
${ }^{54}$ Vgl. Felten u. a. (Anm. 1:2003) 109 Abb. 12.

55 Der betreffende Fundamentrest des Diateichismas südlich des Apollon-Tempels ist zwar in Binderformation verlegt, andererseits ist für dessen unmittelbaren Anschluss an das hellenistische Propylon auch eine der Situation im Westkomplex vergleichbare Läuferkonstruktion nachgewiesen; zur Stärke der Temenosmauer auf der oberen Agora von Pergamon K. Rheidt, Die obere Agora. Zur Entwicklung des hellenistischen Stadtzentrums von Pergamon, IstMitt 42, 1992, 250; E. Pollhammer, Das Kap Kolonna. Eine Festung der Attaliden auf Ägina, in: B. Asamer u. a. (Hrsg.), Temenos. Festgabe für F. Felten und St. Hiller (2002) 99 Taf. 19, 2; ders., Das Kap Kolonna auf Ägina zur Zeit der pergamenischen Herrschaft (ungedr. Diss. Salzburg 2004$) 104$ ff.

${ }^{56}$ Mit diesem Maß entspricht der Durchgang etwa der ebenfalls mit Spurrillen versehenen, $2.32 \mathrm{~m}$ breiten Schwelle des hellenistischen Propylons am Südhang.

${ }^{57}$ Vgl. Felten u. a. (Anm. 1:2003) 52; Felten u. a. (Anm. 1:2004) 114.
} 


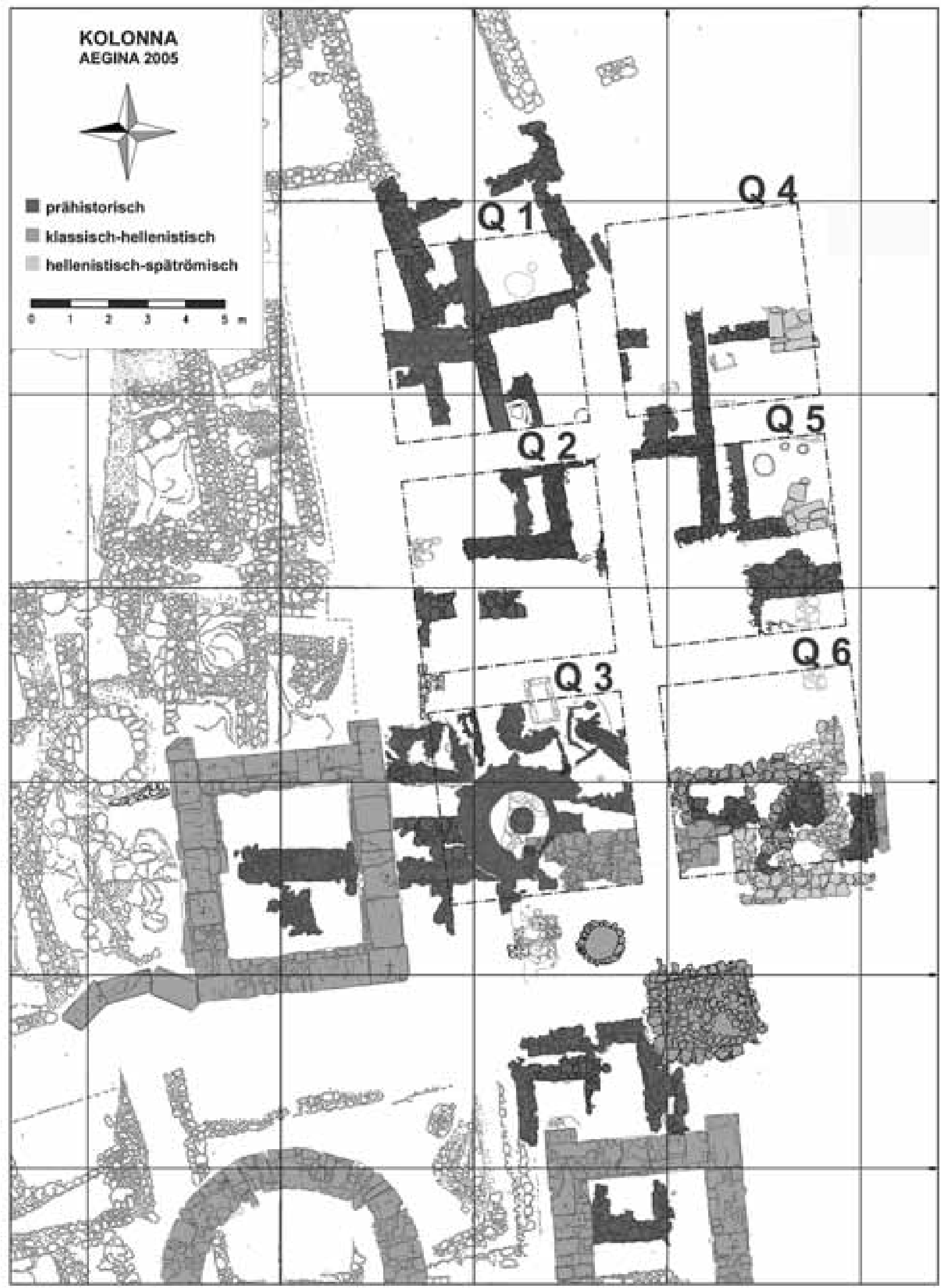

25 Prähistorische Innenstadt. Gesamtplan Areal Südhügel 


\section{Südhügel}

\section{a. Allgemein}

Die Grabungen am sog. Südhügel (Abb. 25) wurden in den Quadranten Q1, Q2, Q5, Q6 und vor allem in Q3 durchgeführt ${ }^{58}$. Bereits im Frühjahr 2005 wurden die im Jahr zuvor geborgenen archäozoologischen und archäobotanischen Reste untersucht; diese Arbeiten finden im Rahmen des von INSTAP geförderten Projekts »Aegina Kolonna - subsistence and more« statt ${ }^{59}$.

\section{b. Quadrant Q1}

Bereits im Jahr 2003 wurde die Oberkante des Steinkistengrabes 2003/051 erreicht. Bei den aktuellen Grabungen wurden das Grab geöffnet und die Skelettreste geborgen (Abb. 26). Im ca. $0.4 \times$ $0.4 \mathrm{~m}$ großen Grab lag über einer dünnen Kieselschicht in seitlicher Hockerlage das Nord-Süd orientierte Skelett eines Kleinkindes. Mit Ausnahme weniger sehr kleiner, vermutlich mittelbronzezeitlicher Scherben war das Grab fundleer. Die Grablegung erfolgte wahrscheinlich von dem rund $0.2 \mathrm{~m}$ höher liegenden Fußboden aus $(2003 / 036)^{60}$.

\section{c. Quadrant Q2}

Beim Abtiefen im Südteil von Quadrant Q2 wurden rein prähistorische Schichten erreicht, die in die späte Mittlere Bronze-

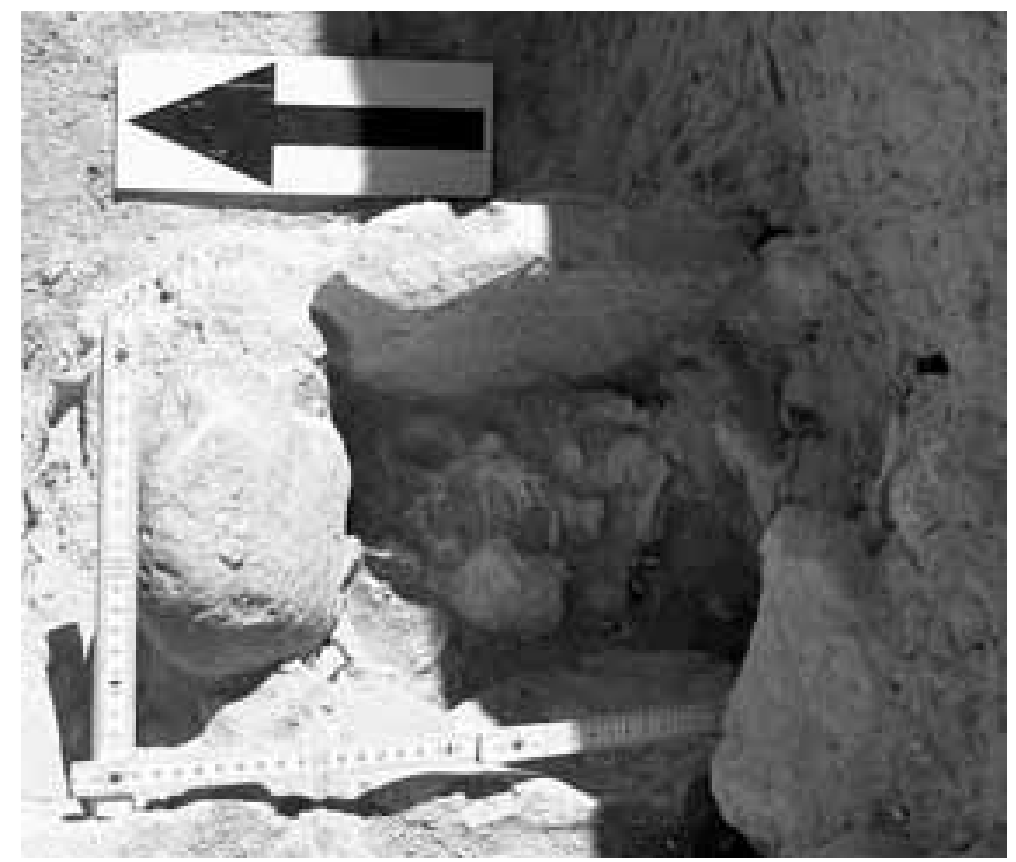

26 Q1. Kistengrab 2003/051 zeit gehören (Abb. 25). Unter den Funden sind mattbemalte Scherben mit typischen Motiven - wie hängende und sich überschneidende Kreissegmente ${ }^{61}$ ('Girlanden’) - besonders zahlreich. Darüber hinaus wurden einige Fragmente mit noch nicht bekannten Töpferzeichen und diskusförmige Webgewichte des ‘minoischen’ Typs aus lokalem Ton gefunden sowie ein teilweise durchbohrter, spulenförmiger Gegenstand aus Marmor (Abb. 27, 1-7) ${ }^{62}$. Die Bohrung in der Querachse mit Resten von Metall dürfte einen Stift aus Holz oder Metall fixiert haben, der in die Längsachse gesteckt wurde; die Funktion des Steingegenstandes ist noch unklar.

${ }^{58}$ Zur Dokumentation- und Grabungsmethode s. Felten u. a. (Anm. 1:2003) 56. Mit Mitteln des Projekts »SCIEM 2000« wurde die Teilnahme von D. Knauseder (Ausgrabung, Material- und Bauaufnahme) finanziert. Die Verfasser danken G. Klebinder-Gauß für eine kritische Durchsicht des Manuskripts über den Südhügel.

${ }^{59}$ Das Projekt wird von G. Forstenpointner, A. Galik und G. Weissengruber (archäozoologische Analysen), K. Grossschmidt und F. Kanz (anthropologische Untersuchungen) sowie U. Thanheiser (archäobotanische Analysen) gemeinsam mit W. Gauß und R. Smetana im Rahmen des Projekts »SCIEM 2000« durchgeführt; vgl. dazu einen ersten Bericht von G. Weissengruber u. a., Mammalian Biology 69, 2004, 44.

${ }^{60}$ Abhub Q1/29.

${ }^{61}$ Vgl. etwa H.-B. Siedentopf, Mattbemalte Keramik der Mittleren Bronzezeit, Alt-Ägina IV 2 (1991) Taf. 95. 96; R. Buck, Hesperia 33, 1964, 268 Motiv 78; Taf. 43.

62 Abb. 27, 1 (Q2/12-6); Abb. 27, 2 (Q2/16-1); Abb. 27, 3 (Q2/17-1); Abb. 27, 4 (Q2/16-11); Abb. 27, 5 (Q2/17-2); Abb. 27, 6 (Q2/18-12); Abb. 27, 7 (Q2/20-13). 
1
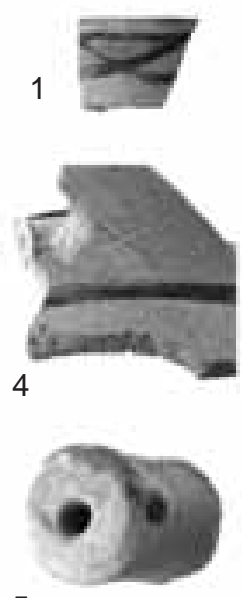

5

27 Q2. Spätmittelbronzezeitliche Keramik
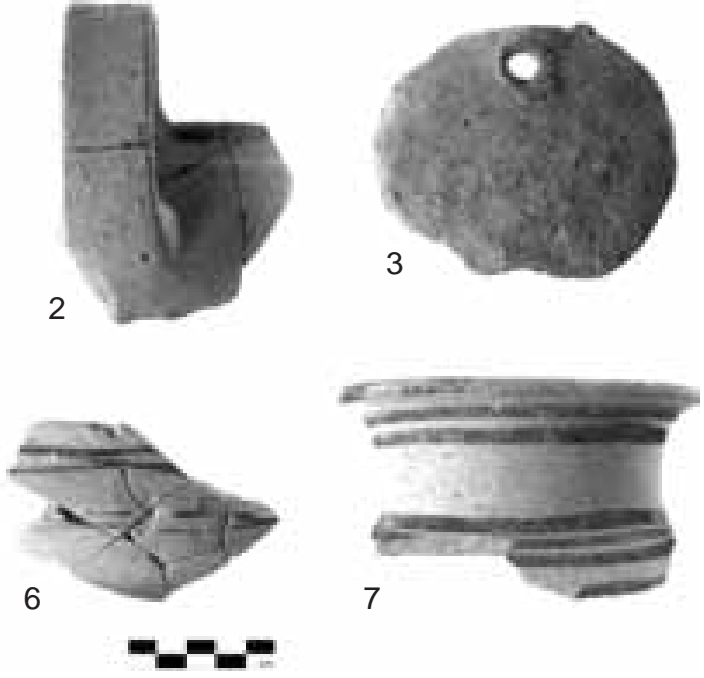

7

Wie bereits in den vorhergehenden Jahren in den angrenzenden Quadranten Q1, Q4 und Q5 beobachtet werden konnte, ist auch der gesamte Bereich von Q2 von spätrömischen Gruben gestört ${ }^{63}$. Im Zuge der Grabungen wurde die Fortsetzung der Nord-Süd verlaufenden Mauer 2002/136 und der sog. Kiesstraße 2002/161 freigelegt.

Die Mauer 2002/136 setzt sich nach Süden fort und bildet mit der Ost-West verlaufenden, zweischaligen, $0,55 \mathrm{~m}$ breiten Mauer 2005/001 eine Ecke. Weitere freigelegte Mauerzüge zeigen, dass auf engstem Raum verschiedene Umbauten, einschließlich Zuschlichtungen, vorgenommen wurden. So setzt sich die bei den Grabungen 2002 in Quadrant Q1 freigelegte Ost-West verlaufende Mauer 2002/084 in Q2 fort, wo sie im Mauerkopf 2005/012 endet. Zu einem späteren Zeitpunkt wurde der Bereich zwischen dem Mauerkopf 2005/012 und der Nord-Süd verlaufenden Mauer 2002/136 mit Mauer 2005/002 zugeschlichtet (Abb. 25. 28).

\section{d. Quadrant Q3}

\section{Apsidenbau}

In Quadrant Q3 wurde der im Jahr 2004 teilweise angegrabene Apsidenbau (Abb. 29) weiter untersucht ${ }^{64}$. Die erhaltenen Mauern des Apsidenbaus werden durch ein Steinpflaster abgedeckt, das am Anfang der Mittleren Bronzezeit angelegt worden ist. Wahrscheinlich steht es in Zusammenhang mit der Errichtung des sog. Großsteinbaus (Phase 1). Unter dem Steinpflaster wurden weitere Teile des Apsidenbaus freigelegt. Die stratigraphischen Beobachtungen und Funde bestätigen eine Datierung in den Übergang von der ausgehenden Frühen Bronzezeit (FH III) zur Mittleren Bronzezeit bzw. an den Beginn der Mittleren Bronzezeit. Teile des weißen Wandverputzes haben sich gut erhalten; sie wurden gereinigt und gefestigt. 2006 sollen im Bereich des Apsisraumes weitere Grabungen erfolgen.

\section{Bereich Töpferofen}

Intensive Arbeiten betrafen den Zugangsbereich des Töpferofens (Abb. 30-37). Dabei wurden die Fläche unmittelbar vor dem westlichen Quaderbau untersucht und ein Schnitt durch den Töpferofen angelegt. Die Grabungen im Zugangsbereich des Töpferofens bestätigen den Zeitpunkt der Anlage des Ofens in der Späten

\footnotetext{
${ }^{63}$ s. Felten u. a. (Anm. 1:2003) 59.

${ }^{64}$ s. Felten u. a. (Anm. 1:2005) 30.
} 
Bronzezeit (SH IIIA) ${ }^{65}$. Wie bereits in den letzten Jahren beobachtet, wurde der Zugangsbereich zum Töpferofen mehrfach aufgehöht (Abb. 30, 1) ${ }^{66}$. Die Abfallgrube des Töpfereibetriebs wurde noch nicht gefunden. Unmittelbar unter dem Ofen wurden Mauern des 'Großsteinbaus' aus der Mittleren Bronzezeit freigelegt, was bedeutet, dass beim Bau des Ofens Teile des 'Großsteinbaus' und die darüberliegenden Reste der beginnenden Späten Bronzezeit zerstört worden waren (Abb. 30, 2) ${ }^{67}$.

Der Bereich zwischen Töpferofen und westlichem hellenistischem Quaderbau war durch die Grabungen von G. Welter teilweise gestört (Abb. 31, 1) ${ }^{68}$. Im ungestörten Bereich wurde eine Abfolge von Fußbodenhorizonten beobachtet, die in die Mittlere Bronzezeit gehört. Auf dem obersten erhaltenen Fußboden wurde qualitätsvolle Keramik gefunden, u. a. eine vollständig erhaltene, zur Gänze bemalte, scheibengedrehte minoische Kanne in Sturzlage (Abb. 31, 2) ${ }^{69}$. Unbemalte oder vollkommen bemalte minoische Feinkeramik, wie karinierte Tassen und flache Schalen (Abb. 32, 1-3), ein unbemalter 'Bridge Spouted Jar' und eine Kanne mit weißem 'Trickle-Pattern' (Abb. 32, 4-5) $)^{70}$, fanden sich zusammen

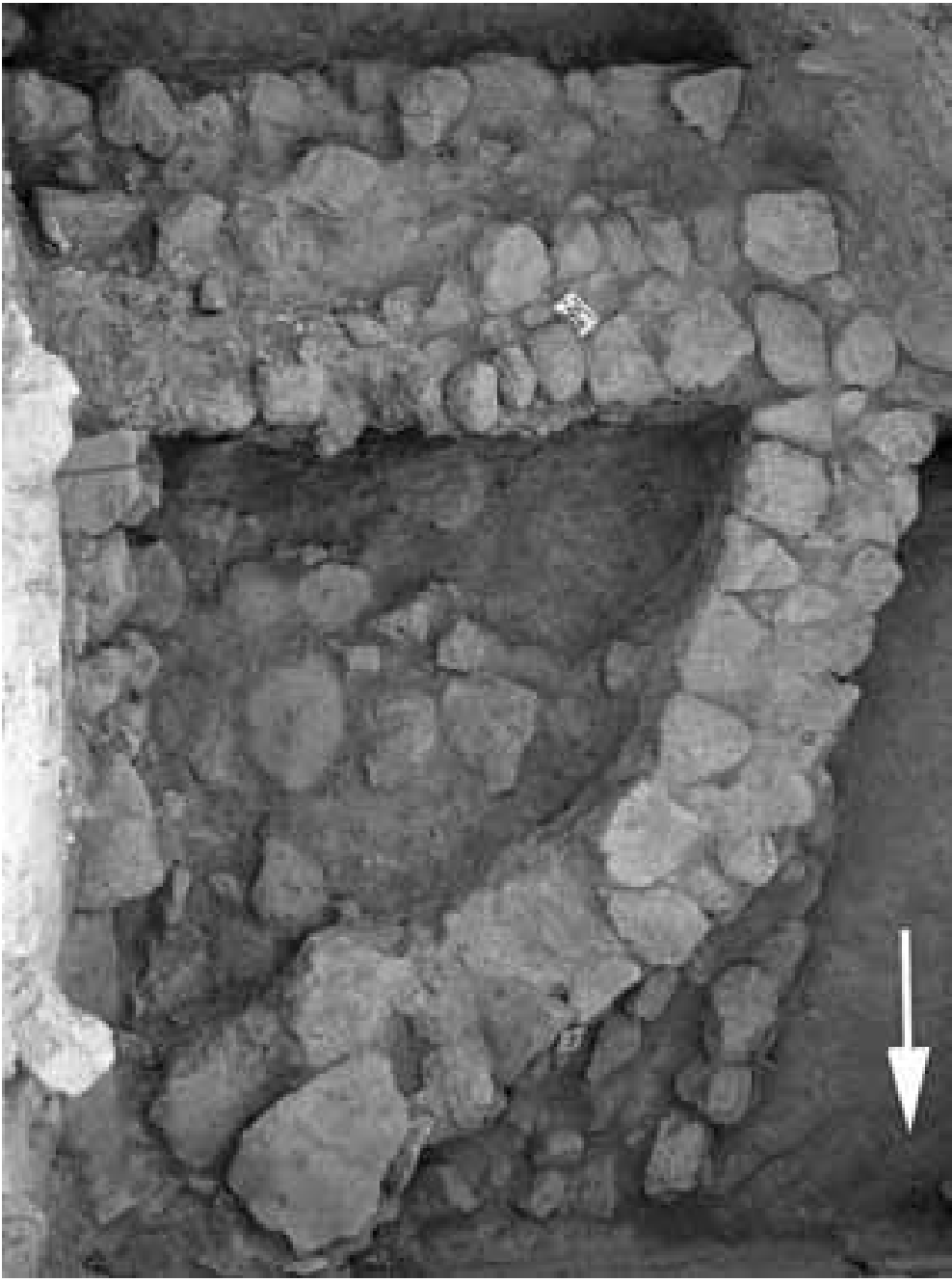

29 Q3. Apsidenbau mit zahlreichen weiteren lokal äginetischen Gefäßen und Gefäßteilen, die zerschlagen auf dem Fußboden lagen oder in der harten Lehmziegelauffüllung über dem Boden steckten (Abb. 33).

Bei den äginetischen Gefäßen handelt es sich um Gebrauchs- und Feinkeramik, darunter ein Deckel mit bislang seltener matter Hell-auf-Dunkel-Bemalung ${ }^{71}$, ein Miniatur-Pithos mit matter Dunkel-auf-Hell-Bemalung, große Schulterhenkelgefäße mit geritztem Dekor in Form hängender Kreissegmente (Abb. 34, 1-3) ${ }^{72}$ sowie geschlossene, enghalsige Gefäße (Amphoren, Hydrien oder Kannen), deren Schulterdekor mit dem Dekor der drei mattbemalten Amphoren aus dem Schachtgrab von Ägina übereinstimmt (Abb. 34, 4-7) ${ }^{73}$.

65 s. Felten u. a. (Anm. 1:2005) 28 f.; W. Gauß, Ägina Kolonna in frühmykenischer Zeit, in: Keimelion. Festschrift S. Deger-Jalkotzy (2006) 163-172.

${ }^{66}$ s. Felten u. a. (Anm. 1:2004) 123 und Abb. 29, 10. 11; Felten u. a. (Anm. 1:2005) 28.

${ }^{67}$ s. Felten u. a. (Anm. 1:2004) 121-122.

68 s. Felten u. a. (Anm. 1:2005) 26; W. Gauß (s. Anm. 65).

${ }^{69}$ Abb. 31, 2 (Q3/181-5)

${ }^{70}$ Abb. 32, 1 (Q3/179-14); Abb. 32, 2 (Q3/182-20); Abb. 32, 3 (Q3/181-4); Abb. 32, 4 (Q3/198-5); Abb. 32, 5 (Q3/198-1).

${ }^{71}$ Hell auf Dunkel bemalte Keramik lokaler Produktion ist bislang sehr selten; vgl. dazu auch die naturwissenschaftlichen Untersuchungen von Pr-197 (H. Mommsen u. a. in: E. Pohl - U. Recker - C. Theune [Hrsg.], Archäologisches Zellwerk. Beiträge zur Kulturgeschichte in Europa und Asien. Festschrift H. Roth [2001] 92-93 Tab. 3 [Gattung 9]). Bei den Grabungen am 'Südhügel' wurde ein anpassendes Randfragment (Q3/87-25) in Schichten der fortgeschrittenen Mittleren Bronzezeit gefunden.

72 Abb. 34, 1 (Q3/179-25); Abb. 34, 2 (Q3/198-8); Abb. 34, 3 (Q3/198-6).

73 Abb. 34, 4 (Q3/198-10); Abb. 34, 5 (Q3/198-3); Abb. 34, 6 (Q3/183-1); Abb. 34, 7 (Q3/178-19). Zu den Amphoren aus dem Schachtgrab von Ägina s. I. Kilian-Dirlmeier, Das mittelbronzezeitliche Schachtgrab von Ägina, Alt-Ägina IV 3 (1997) 66 


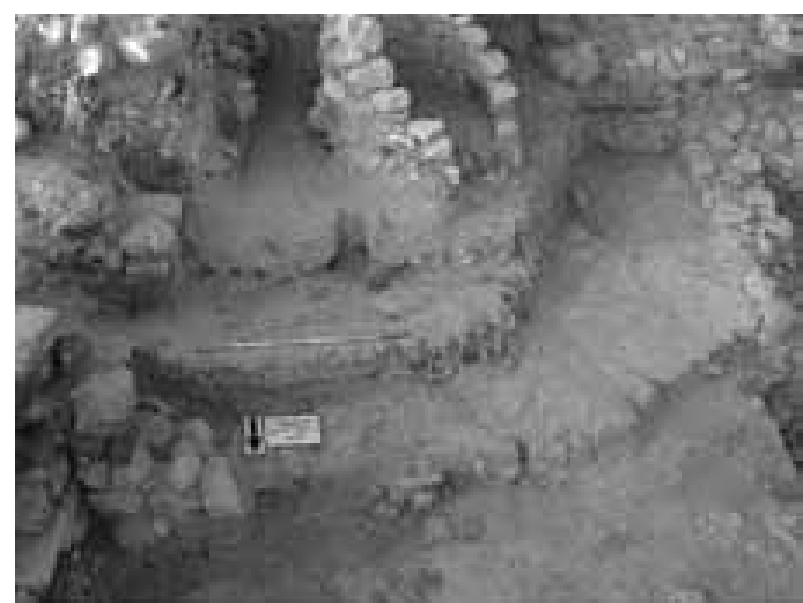

1

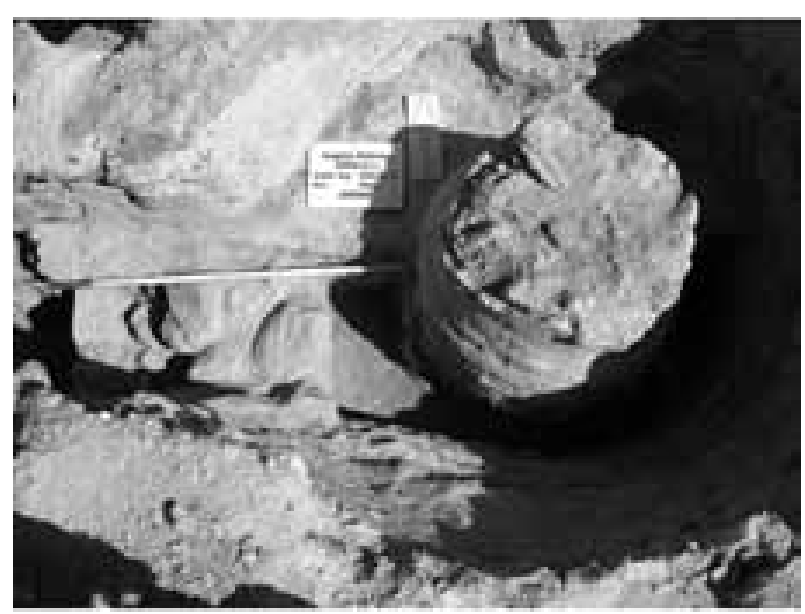

2

30 Q3. Zugangsbereich Töpferofen (1) sowie Schnitt im Ofen mit Mauer 'Großsteinbau’ (2)
In einer Grube, die teilweise durch die Grabungen von G. Welter geschnitten worden war, kamen neben qualitätsvoller Keramik der Mittleren Bronzezeit (Abb. 35, 1-3) ${ }^{74}$ zwei bislang einzigartige Funde, zylindrische Tonobjekte mit figürlichen Darstellungen, zutage. In der Frühen und Mittleren Bronzezeit des griechischen Festlandes sind Tonsiegel und Tonstempel selten ${ }^{75}$. Figürliche Darstellungen auf Tonsiegeln sind Ausnahmen ${ }^{76}$ und machen die beiden äginetischen Neufunde daher umso bemerkenswerter. Nach makroskopischer Analyse ist der Ton beider Objekte lokal äginetisch. Einer der Tonzylinder ist weitgehend erhalten und kann aufgrund der Darstellungen im Negativ als Rollsiegel bezeichnet werden (Abb. 36, 1) ${ }^{77}$. Das tief eingegrabene Muster lässt einen sitzenden Menschen/Mann mit ausgestrecktem Arm erkennen. Vor dem Sitzenden befinden sich ein Skorpion mit erhobenem Schwanz und eine stilisierte Spirale. Der andere Tonzylinder ist mit einem Relief verziert, sodass die Bezeichnung 'Siegel' eigentlich nicht zutreffend ist: Es handelt sich eher um einen Stempel oder Stempelroller (Abb. 36, 2) ${ }^{78}$, auf dem mindestens zwei Sitzende mit erhobenen Armen dargestellt sind. In dem sehr flachen Relief sind zudem mindestens zwei Skorpione (groß und klein) sowie zwei gegenständig angeordnete Vierfüßler/Carpiden zu erkennen. Der Herstellungsvorgang des positiven Reliefs ist gegenwärtig noch unklar $^{79}$. Beide Objekte wurden im Bereich des 'Großsteinbaus' gefunden und weisen auf die Existenz von Verwaltungsstrukturen hin, welche bislang nur aus dem minoischen Kreta bekannt sind ${ }^{80}$.

Kat. 19. Die Gefäße sind jetzt im Museum von Ägina-Kolonna ausgestellt; zu vergleichbaren Motiven s. Siedentopf (Anm. 61) Taf. 48, 216-219.

${ }^{74}$ Die Auszählung der Funde ist noch nicht abgeschlossen. Die Grube enthielt fast ausschließlich mittelbronzezeitliche Keramik einer fortgeschrittenen bis späten Entwicklungsstufe. Abb. 35, 1 (Q3/204-44); Abb. 35, 2 (Q3/204-20); Abb. 35, 3 (Q3/204-33).

${ }^{75}$ Vgl. die Zusammenstellungen bei I. Pini, Minoische und helladische Tonsiegel, in: Centre G. Glotz (Hrsg.), Aux origines de l'hellénisme. La Crète et la Grèce. Hommage à Henri van Effenterre (1984) 73-81; ders., CMS V Suppl. 1B (1993) XXVII-XXIX; I. Kilian-Dirlmeier, Die bronzezeitlichen Gräber bei Nidri auf Leukas (2005) 169 Liste 6 (nach Pini 1993 mit Ergänzungen). s. außerdem das Fragment eines tönernen Siegelrings vom Nordabhang der Athener Akropolis, CMS V Suppl. 3, 1 (2004) 186.

${ }^{76}$ Pini (Anm. 75) 76 mit Anm. 32 verweist auf ein Tonsiegel aus Gournia mit der Darstellung von Vierfüßlern.

77 Abb. 36, 1 (Q3/205-1).

78 Abb. 36, 2 (Q3/204-1).

${ }^{79}$ Die Verf. danken I. Pini für Anregungen und Informationen.

${ }^{80}$ Pini (Anm. 75) 80 schreibt zu spätminoischen Tonstempeln: »Die Verwendung der hier erörterten spätminoischen Tonstempel und Model läßt sich kaum sicher bestimmen. Sie können natürlich quasi als Ersatz gedient haben für das Originalsiegel bzw. den metallenen Siegelring und tatsächlich zum Versiegeln benutzt worden sein. Denkbar wäre auch, daß sie Graveuren als Musterstempel für Zweitanfertigungen oder Varianten dienten. Auch könnte man sich vorstellen, daß Archivverwalter Kopien bestimmter Siegel erhielten, um überprüfen zu können, ob die Versiegelungen tatsächlich mit demselben Siegel vorgenommen waren. Die wenigen bis heute gefundenen Beispiele sprechen indes nicht dafür, daß eine der hier angedeuteten Möglichkeiten allgemeiner Brauch war.» 

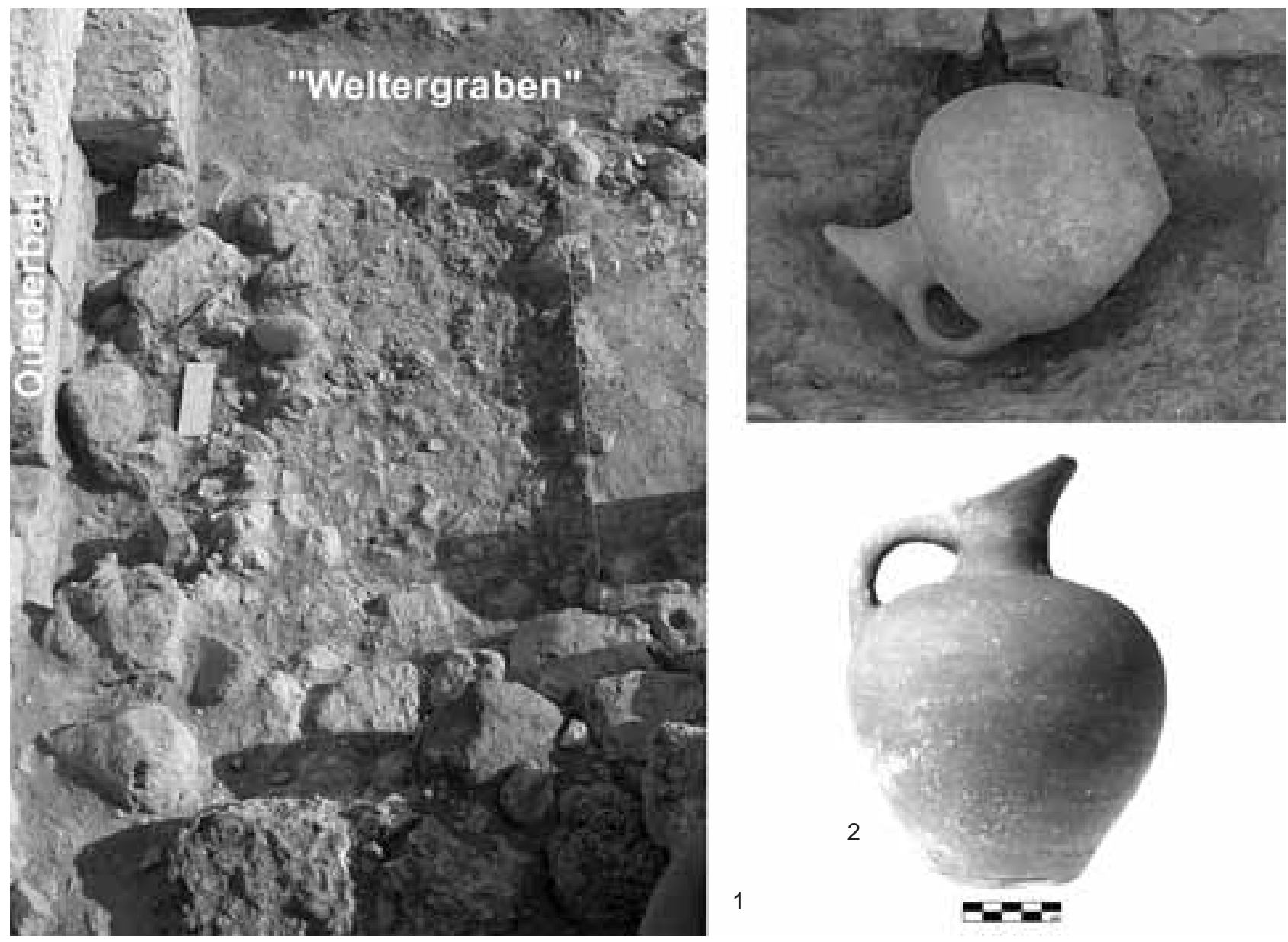

31 Q3. Laufhorizont mit 'Weltergraben’ (1) und minoische Kanne (2)

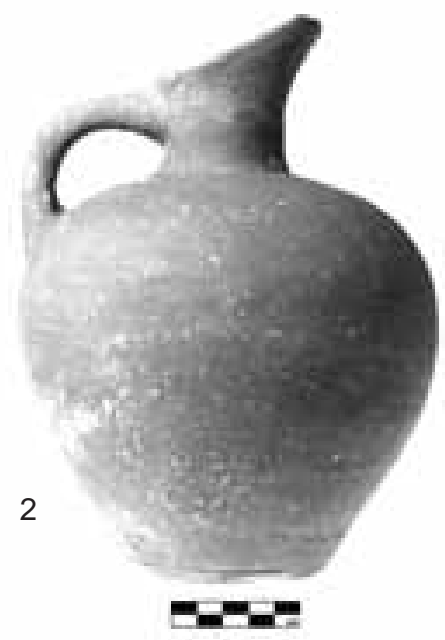

1

Unter den mittelbronzezeitlichen Bodenschichten wurden erneut Mauerreste freigelegt, die bereits in die Frühe Bronzezeit (FH III) gehören (Abb. 37). Die keramischen Funde sind nicht besonders aussagekräftig, sichern jedoch eine Datierung in die Frühe Bronzezeit. Die Grabungen wurden am Beginn einer sehr harten Geröllpackung eingestellt; möglicherweise handelt es sich dabei um eine Packung, die den unregelmäßig verlaufenden Felsboden ausgleichen sollte.
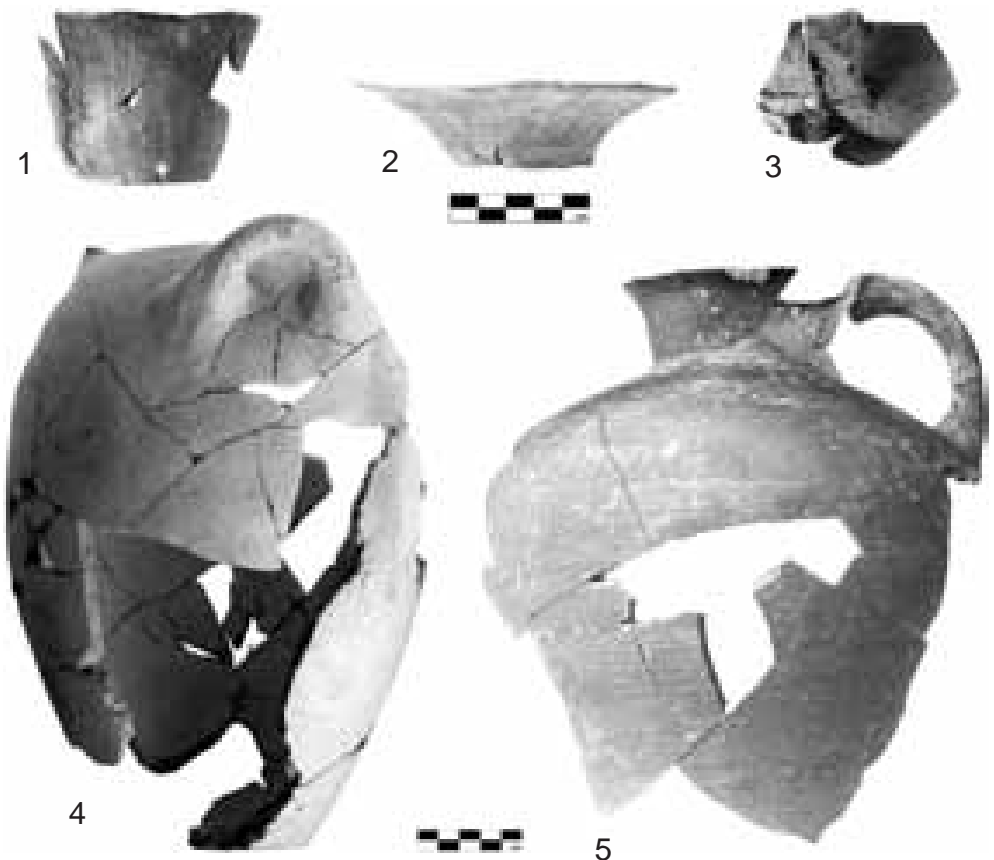

32 Q3. Minoische Keramik 


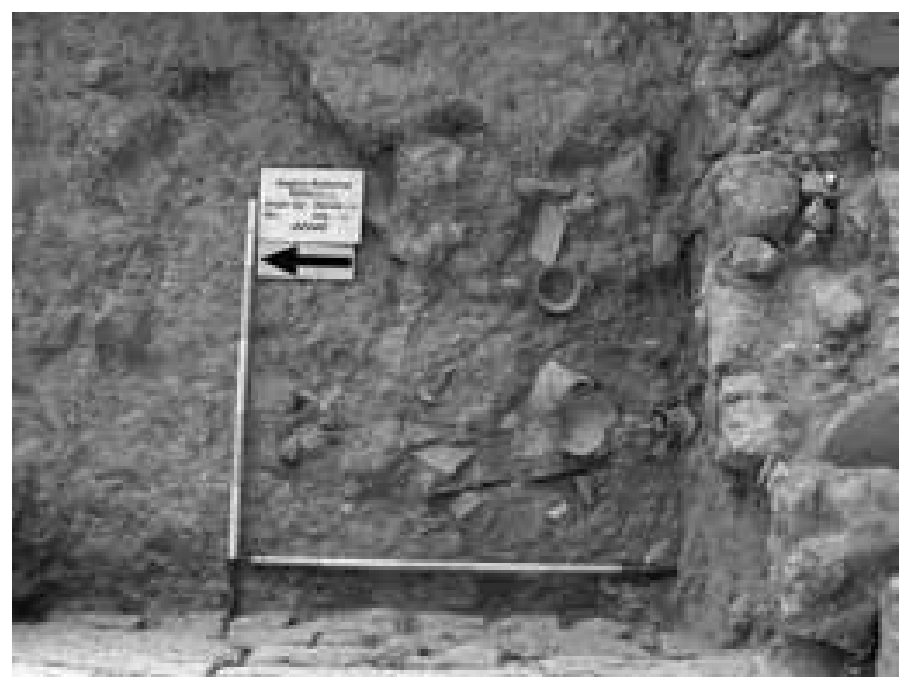

33 Q3. Fußboden mit zerschlagener Keramik

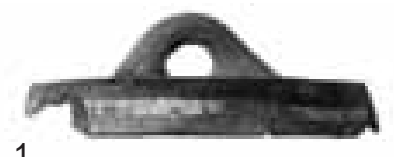

1

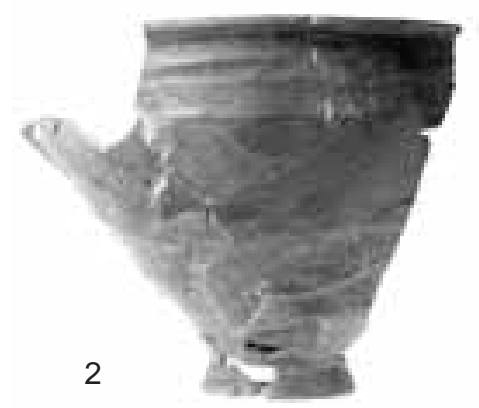

3
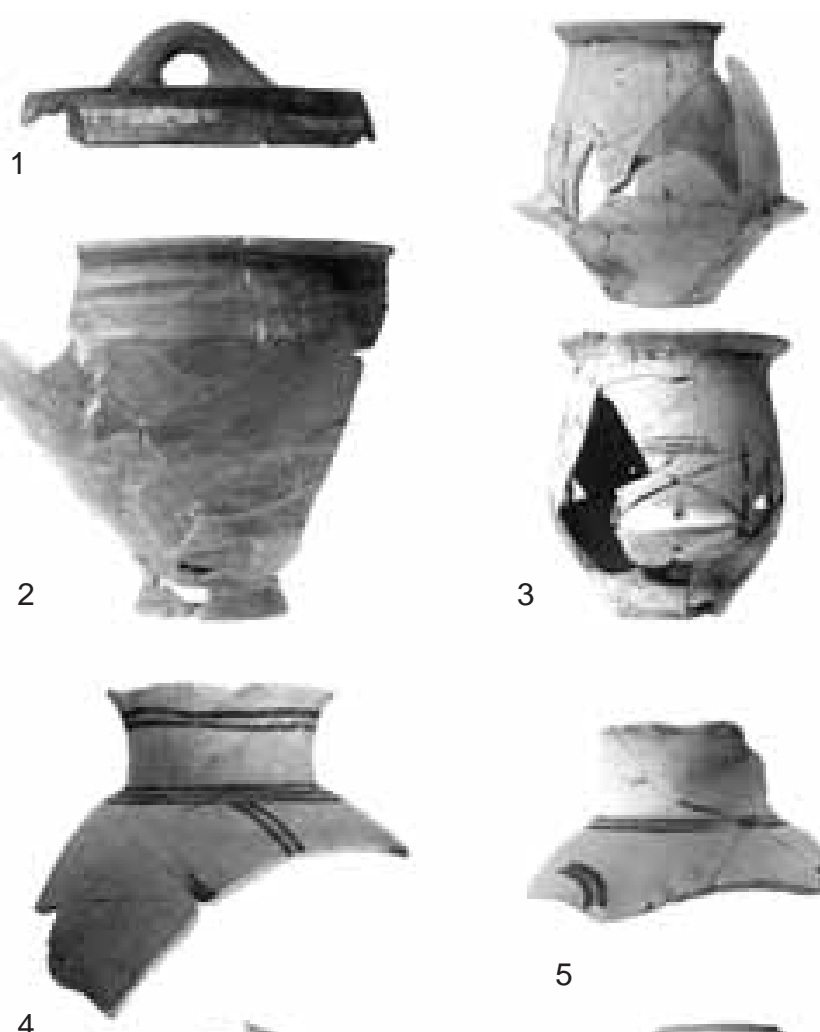

4

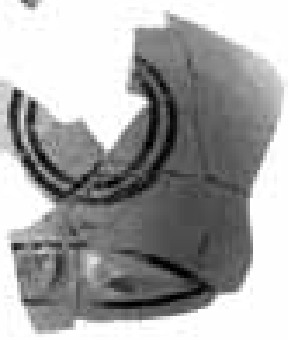

6

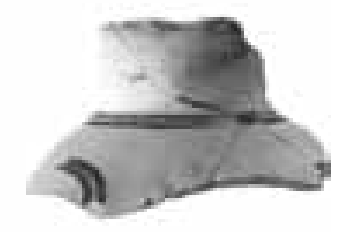

5

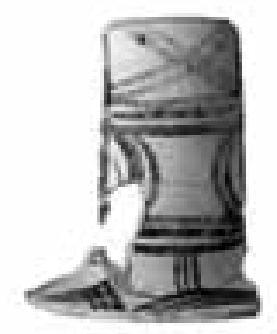

e. Quadrant Q5 und Profilsteg Q4-Q5

(Abb. 25. 38, 1-3)

Im Quadrant Q5 und im Steg zwischen den Quadranten Q4 und Q5 wurde die Fläche in der Nordhälfte weiter abgetieft und reine Schichten der Mittleren Bronzezeit wurden erreicht. Im Zuge der Grabungen wurde die Fortsetzung der nord-südlich verlaufenden Mauer 2002/064 und der Ost-West verlaufenden Mauer 2005/027 (in Q4) freigelegt. Eine weitere nord-südlich verlaufende Mauer (2005/028) kam im Erdsteg zwischen Q4 und Q5 zutage.

Auf engem Raum finden sich zahlreiche prähistorische Mauerreste, die zu verschiedenen Umbauphasen gehören und teilweise direkt übereinander liegen. Dies und die spätrömischen Abfallgruben, die den Verlauf der prähistorischen Mauern stören, erschweren eine chronologische Einordnung und funktionelle Zuordnung (Abb. 25). Bislang wurden in Q5 in direkter Abfolge mehrere Fußböden oder Laufhorizonte beobachtet (2005/029, /034, /039, /041, /045). Die zeitlich einzuordnenden Funde gehören in die fortgeschrittene bis späte Mittlere Bronzezeit bzw. in die beginnende Späte Bronzezeit. Neben der üblichen mattbemalten Keramik, wie etwa offenen Gefäßen mit einem Dekor aus hängenden Kreissegmenten (Abb. 38, 3), wurden auch Fragmente der bislang in Ägina nicht so verbreiteten 'Panelled-Cups' mit Spiraldekor gefunden (Abb. 38, 2) ${ }^{81}$.

\section{f. Quadrant Q6}

Im Quadrant Q6 wurden im Tiefschnitt bereits 2004 Schichten des Übergangs von der Frühen zur Mittleren Bronzezeit (FH III/MH) erreicht. Die Fortsetzung der Grabungen hatte das Auffinden sicherer Frühhelladisch-III-Schichten zum Ziel. Nach wenigen Abhüben fand sich ein eindeutiger Frühhelladisch-III-Fußbodenhorizont, die Grabungen wurden somit an dieser Stelle vorläufig eingestellt.

Unter der Sohle von Schacht $1^{82}$ wurde die Fortsetzung der zweiten Phase des 'Großsteinbaus’ festgestellt (Abb. 39). Aufgrund der stratigraphischen Beobachtungen zeichnet sich ab,

\footnotetext{
${ }^{81}$ Abb. 38, 2 (Q5/9-6); Abb. 38, 3 (Q5/10-7).

${ }^{82}$ Felten u. a. (Anm. 1:2004) 116-118 Abb. 20-22.
} 


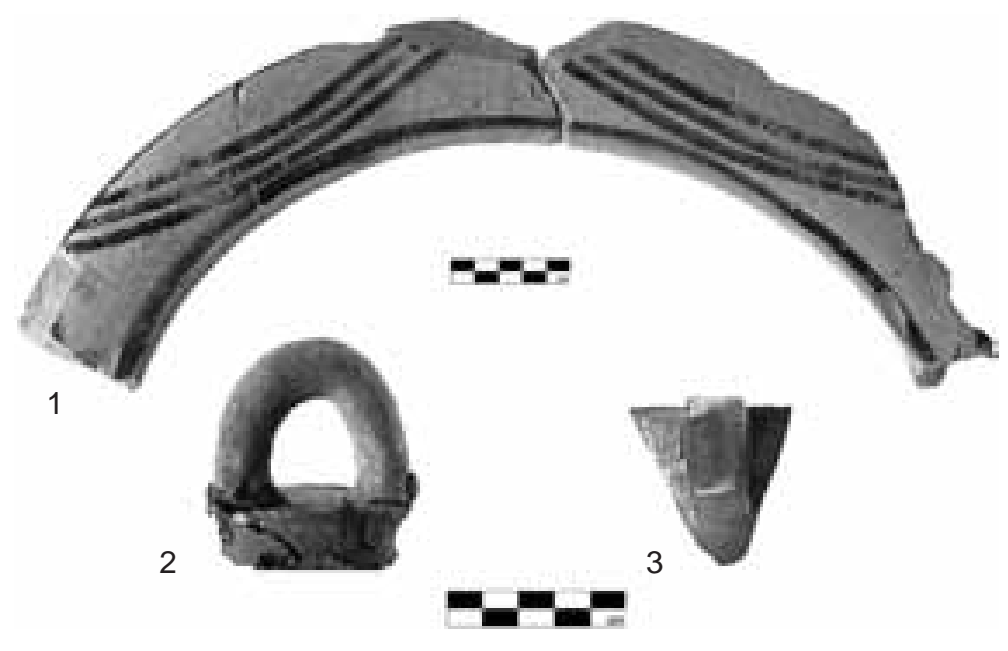

35 Q3. Keramik der Mittleren Bronzezeit

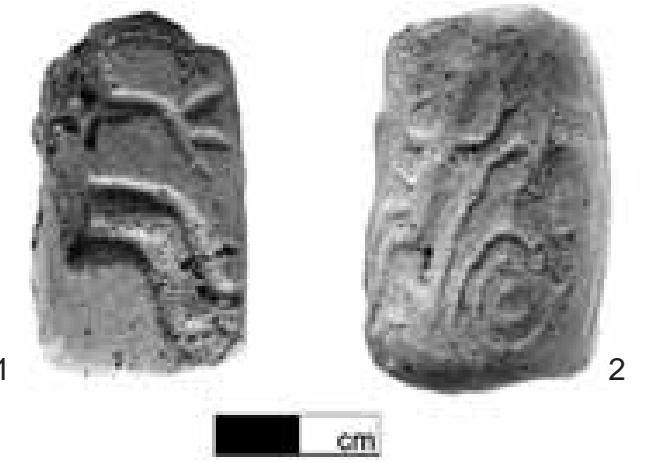

36 Q3. Tonzylinder

dass der in der Mittleren Bronzezeit errichtete 'Großsteinbau' bis zum Beginn der Späten Bronzezeit genutzt wurde. Eine bereits im Jahr 2003 gefundene Ansammlung von Späthelladisch-I-Gefäßen dürfte damit zur spätesten Nutzungsphase der Anlage gehören (Q6/18) ${ }^{83}$.

Bei der Reinigung der Mauer des 'Großsteinbaus' (Phase 2) wurde der Steinversturz unmittelbar südlich von Schacht 1 entfernt. Dabei zeigte sich, dass das Ost-West verlaufende Mauerstück 2005/008 der letzte Rest der südlichen Begrenzungsmauer des Schachtes ist.

Zur Ermittlung der gesamten nordsüdlichen Ausdehnung des 'Großsteinbaus' war eine Erweiterung des Quadranten Q6 nach Süden notwendig. Dabei wurden die Reste einer ungefähr ostwestlich verlaufenden Quadermauer festgestellt (Abb. 40). Es könnte sich um eine Einfriedungsmauer handeln, welche die beiden hellenistischen Quaderbauten, den Altar und den Rundbau, vom restlichen Heiligtum der Akropolis von Ägina abgetrennt hat. Die Nord-Süd verlaufende Mauer des 'Großsteinbaus' reicht bis direkt an die vermutete Begrenzungsmauer bzw. wird von ihr unterbrochen. Damit ist eine nord-südliche Ausdehnung des ‘Großsteinbaus' von mindestens 30 m ge-

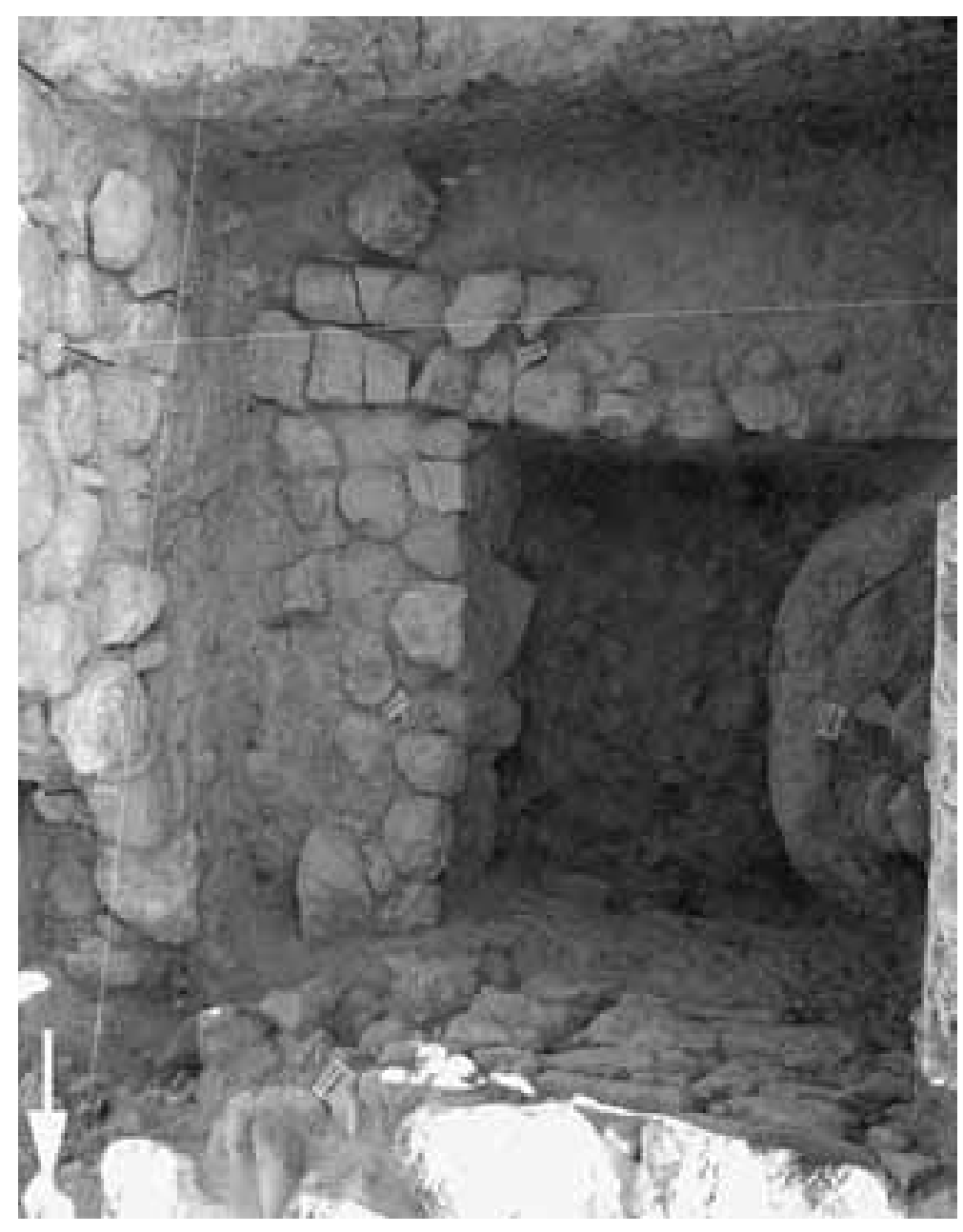

37 Q3. Frühbronzezeitliche Mauern

\footnotetext{
${ }^{83}$ s. Felten u. a. (Anm. 1:2004) 124 und Abb. 30.
} 

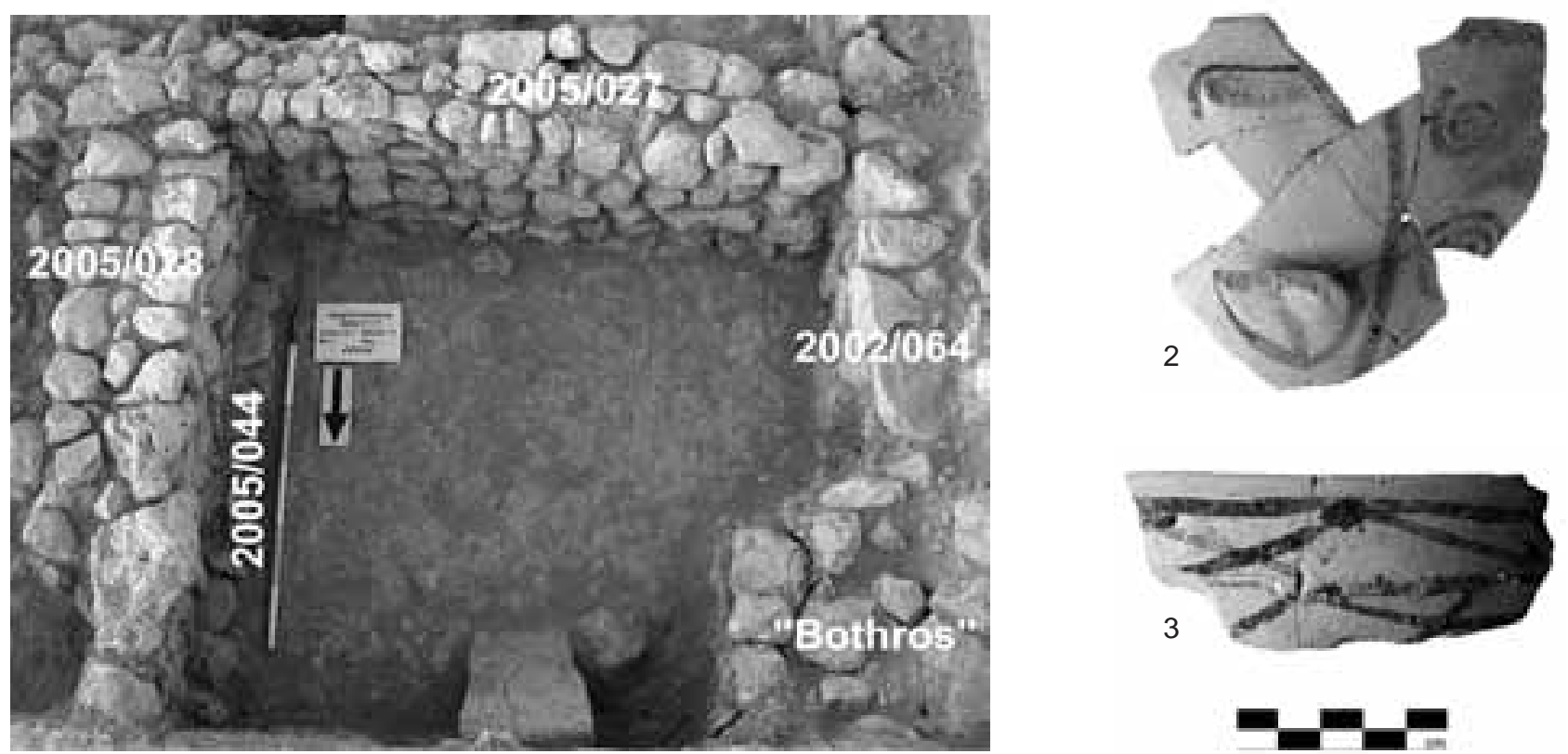

1

38 Q5. Mittelbronzezeitliche Mauern und Keramik

sichert. Mit diesen Ausmaßen gehört das Gebäude zu den größten mittelbronzezeitlichen Anlagen des griechischen Festlandes ${ }^{84}$. Die Untersuchungen in den kommenden Jahren sollen u. a. der Fortsetzung der Einfriedungsmauer und der Ausdehnung des ‘Großsteinbaus' gelten.

\section{g. Profilbegradigung der Südstraße bei dem 'Pithoshaus’}

Bei den Grabungen im Bereich der Befestigungsmauer der sog. Innenstadt wurde eine Ost-West verlaufende Straße ('Südstraße') festgestellt, die vom 'Südtor' der Befestigung am sog. Pithoshaus vorbei in das Zentrum der Siedlung führte. Ein ähnlicher Wegverlauf ist auch für die frühbronzezeitliche Siedlung von Kolonna V anzunehmen, deren Reste bei der Tiefgrabung im Bereich unmittelbar östlich des 'Pithoshauses' festgestellt worden waren ${ }^{85}$. Zur Klärung des Straßenverlaufes im Bereich des 'Pithoshauses' wurde das hoch anstehende Erdprofil neu abgestochen oder abgegraben und zeichnerisch dokumentiert (Abb. 41). Harte, kieselige Schichten, die mit der Straßennutzung in Verbindung stehen, wechseln mit weicheren Lagen. Die keramischen Funde sind aufgrund der begrenzten Grabungsfläche gering und in ihrer Aussagekraft eingeschränkt. Sie zeigen aber dennoch, dass die 'Südstraße' seit der ausgehenden Frühen Bronzezeit (FH III) und während der gesamten Mittleren Bronzezeit mehrfach aufgehöht worden ist. In der späten Mittleren Bronzezeit bzw. am Übergang zur Späten Bronzezeit wurden Teile der Straße vom sog. Pithoshaus der Siedlungsphase Kolonna $\mathrm{X}$ überbaut.

\section{h. Zusammenfassung}

In den Quadranten Q1, Q2 und Q5 konzentrierten sich die Ausgrabungen auf das Erreichen prähistorischer Schichten - in der Regel solche der späten Mittleren Bronzezeit - und auf die Planaufnahme. Im gesamten Bereich von Q2 und Q5 erwiesen sich die prähistorischen Schichten durch spätrömische Gruben gestört. Im Gegensatz zu den westlicheren Quadranten Q3 und Q6 wurden hier jedoch Reihen gesichert prähistorischer

\footnotetext{
${ }^{84}$ Vgl. dazu die Untersuchung von R. L. N. Barber in: J. M. Sanders (Hrsg.), ФI $\Lambda \mathrm{O} \Lambda \mathrm{AK} \Omega$ N. Lakonian Studies in Honour of Hector Catling (1992) 11-23.

${ }^{85}$ H. Walter - F. Felten, Die vorgeschichtliche Stadt, Alt-Ägina III 1 (1981) 38 (Kolonna V); 83-84 (Kolonna X, 'Pithoshaus').
} 


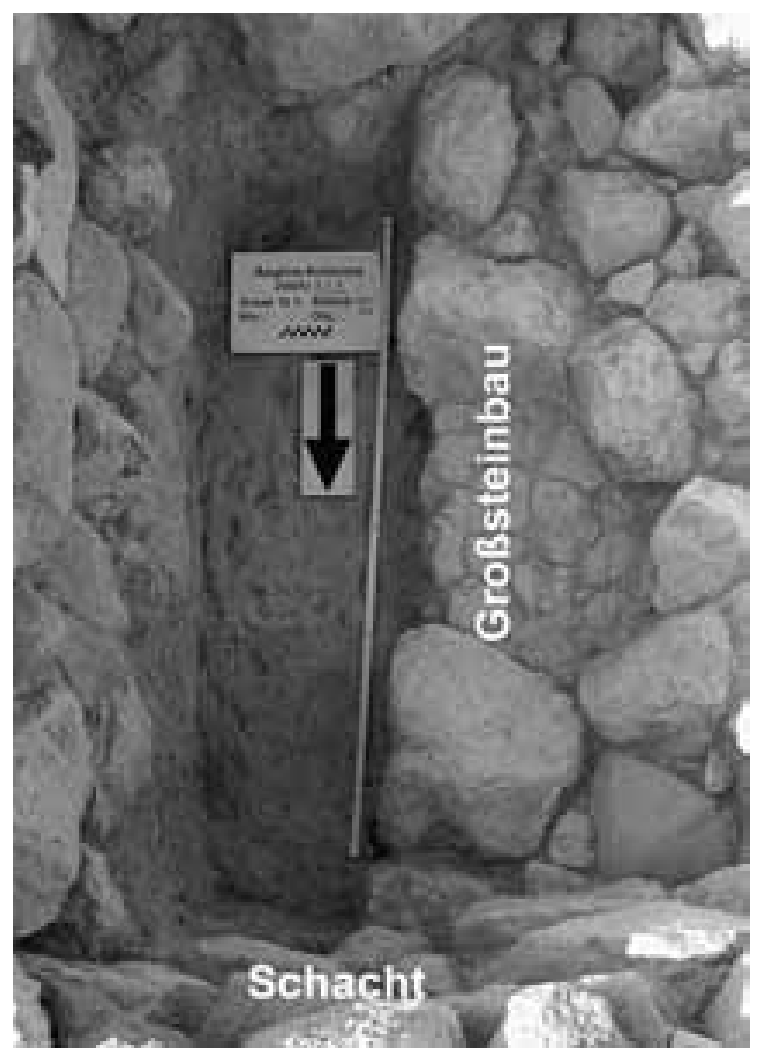

Mauerzüge freigelegt, die kleinteilige und mehrfach umgebaute Raumstrukturen bilden. In den Fußböden bzw. Laufhorizonten aus getretenem Lehm wurden kleine Gruben angelegt, die überwiegend mit aschigem oder kieseligem Material gefüllt sind.

Im Quadranten Q6 wurde der Grabungsbereich nach Süden erweitert, um die Fortsetzung oder das Ende des 'Großsteinbaus’ zu erreichen. Nach gegenwärtigem Stand war die Anlage in Nord-Süd-Richtung mindestens $30 \mathrm{~m}$ lang eine bislang für das griechische Festland in der Mittelbronzezeit außerordentliche Dimension.

Die Entdeckung einer Ost-West verlaufenden Mauer aus gut geschnittenen Quadern in der Erweiterung von Q6 ist von topographischer Bedeutung, da es sich bei der Mauer sehr wahrscheinlich um die Umfassungsmauer eines abgegrenzten Kultbezirkes handelt, der während der pergamenischen Herrschaft mit zwei Quaderbauten, einem Altar und einem Rundbau angelegt worden ist ${ }^{86}$.

Die wichtigsten Entdeckungen der prähistorischen Zeit wurden in Quadrant Q3 gemacht. Zum einen zeigt sich, dass der 'Großsteinbau' weiter nach Westen reichte, als ursprünglich angenommen. Der bisher einzigartige Fund von zwei zylindrischen Tongegenständen mit eingeritzten bzw. plastischen erhabenen figürlichen

${ }^{86}$ Zur Bautätigkeit in Ägina-Kolonna während der Pergamenerherrschaft s. E. Pollhammer in: Asamer u. a. (Anm. 55) 99 ff.; ders., Überlegungen zu den hellenistischen Festungsmauern auf der Akropolis von Ägina, in: B. Asamer - W. Wohlmayr (Hrsg.), Akten des 9. Österreichischen Archäologentages (2003) 165 ff.; ders. (Anm. 55:2004). 
Darstellungen (Menschen/Männer, Skorpione und Vierfüßler/Capriden sowie Spiralen) aus äginetischem Ton weist darüber hinaus darauf hin, dass in Ägina in der fortgeschrittenen Mittleren Bronzezeit Verwaltungsstrukturen existiert haben, die bislang aus dem minoischen Kreta bekannt waren. Der 'Großsteinbau' und die beiden Siegelfunde unterstreichen damit einmal mehr die Bedeutung von Ägina-Kolonna während der Mittleren Bronzezeit.

Prof. Dr. Florens Felten

Prof. Dr. Claus Reinholdt

Dr. Eduard Pollhammer

Dr. Rudolfine Smetana

Fachbereich Altertumswissenschaften/Klassische und Frühägäische Archäologie, Paris-Lodron-Universität Salzburg, Residenzplatz I/II, A-5020 Salzburg

E-Mail: vorname.nachname@sbg.ac.at

Dr. Walter Gauß

Österreichisches Archäologisches Institut, Zweigstelle Athen, Leoforos Alexandras 26, GR-10683 Athen

E-Mail: walter.gauss@oeai.co.hol.gr

Abbildungsnachweis: Abb. 1. 11. 13: Plan, Umzeichnung und digitales Layout C. Reinholdt, E. Pollhammer; Abb. 2. 3-10. 12. 14-24: Photo M. Del-Negro, C. Reinholdt; Abb. 25: Plan W. Gauß, H. Birk; Abb. 26-41: Photo W. Gauß, R. Smetana; digitale Bearbeitung und Layout R. Smetana, B. Wille. Alle Abb. (c) FB Altertumswissenschaften, Klassische und Frühägäische Archäologie, Paris-Lodron-Universität Salzburg. 